\title{
Cellulose Nanofibril/Carbon Nanomaterial Hybrid Aerogels for Adsorption Removal of Cationic and Anionic Organic Dyes
}

\author{
Zhencheng Yu ${ }^{1}$, Chuanshuang Hu ${ }^{1, *}$, Anthony B. Dichiara ${ }^{2} \mathbb{D}$, Weihui Jiang ${ }^{1}$ and Jin Gu ${ }^{1, *(1)}$ \\ 1 College of Materials and Energy, South China Agricultural University, Guangzhou 510642, China; \\ yuzansing2017@stu.scau.edu.cn (Z.Y.); 201820117385@mail.scut.edu.cn (W.J.) \\ 2 School of Environmental and Forest Sciences, University of Washington, Seattle, WA 98195, USA; \\ abdichia@uw.edu \\ * Correspondence: cshu@scau.edu.cn (C.H.); gujin@scau.edu.cn (J.G.); \\ Tel.: +86-20-85282568 (C.H.); +86-20-85280319 (J.G.)
}

Received: 30 November 2019; Accepted: 15 January 2020; Published: 19 January 2020

\begin{abstract}
Advances in nanoscale science and engineering are providing new opportunities to develop promising adsorbents for environmental remediation. Here, hybrid aerogels are assembled from cellulose nanofibrils (CNFs) and carbon nanomaterials to remove cationic dye methylene blue (MB) and anionic dye Congo red (CR) in single and binary systems. Two classes of carbon nanomaterials, carbon nanotubes (CNTs) and graphene nanoplates (GnPs), are incorporated into CNFs with various amounts, respectively. The adsorption, mechanics and structure properties of the hybrid aerogels are investigated and compared among different combinations. The results demonstrate CNF-GnP 3:1 hybrid exhibits the best performance among all composites. Regarding a single dye system, both dye adsorptions follow a pseudo-second-order adsorption kinetic and monolayer Langmuir adsorption isotherm. The maximal adsorption capacities of CNF-GnP aerogels for MB and CR are $1178.5 \mathrm{mg} \mathrm{g}^{-1}$ and $585.3 \mathrm{mg} \mathrm{g}^{-1}$, respectively. CNF-GnP hybrid show a superior binary dye adsorption capacity than pristine CNF or GnP. Furthermore, nearly $80 \%$ of MB or CR can be desorbed from CNF-GNP using ethanol as the desorption agent, indicating the reusability of this hybrid material. Hence, the CNF-GnP aerogels show great promise as adsorption materials for wastewater treatment.
\end{abstract}

Keywords: cellulose nanofibrils; graphene nanoplates; carbon nanotubes; aerogel; organic dyes; adsorption

\section{Introduction}

Dyes are colored organic chemicals typically classified as anionic (acid, reactive, and direct dyes), cationic (all basic dyes), and non-ionic (dispersed dyes) based on their charge upon dissolution in aqueous solutions [1]. These complex molecules are widely used in many industrial fields, such as textile, paper, leather tanning, food processing, plastics, cosmetics, rubber, and printing. The contamination of the hydrosphere with dyes raises serious environmental and sanitary concerns due to their ubiquity, toxicity and deleterious effects on photosynthetic activity in aquatic life due to decreased sunlight penetration [2]. Particularly, methylene blue (MB), one of the most widely used basic dyes in the printing and textile industries, can cause a variety of harmful effects, such as eye burns, gastrointestinal tract and skin irritation [3]. As a typical direct azo dye, Congo red (CR) is mainly applied in a relatively large dosage for dyeing biological samples, and can increase the risk of cancer if absorbed into the human body [4]. Currently, there are various industrial methods for treating waste dye solutions, including adsorption, microbial treatment, chemical oxidation or reduction, flocculation precipitation, ozone oxidization, chemical precipitation, nanofiltration, catalytic degradation etcetera [5-7]. Due to 
its simple operation and low cost, adsorption is widely used as a commercial way to remove organic dyes from aqueous solutions [8].

Recently, carbon nanomaterials have attracted a broad interest in pollutant adsorption. Among them, carbon nanotubes (CNTs) are comprised of one or several sheets of hexagonally packed carbon atoms rolled into concentric seamless cylinders; these exhibit strong mechanical properties, a high aspect ratio, excellent chemical stability and a large specific surface area, which make them desirable for dye adsorption [9-11]. The adsorption mechanism of organic compounds on carbon nanomaterials can be described as an interplay between different intermolecular forces (i.e., hydrophobic, van der Waals forces, $\pi-\pi$ bonding, hydrogen bonding, and electrostatic interactions), whose contributions depend on the adsorbate nature and the surface chemistry of the nano-adsorbent [12]. Another type of carbon nanomaterial, graphene, is a planar honeycomb-shaped nanomaterial consisting of six-member rings with a large specific surface area (theoretical value of $2630 \mathrm{~m}^{2} \mathrm{~g}^{-1}$ ) [13]. It is more easily prepared than CNT and shows an extensive application prospect in the removal of organic and inorganic pollutants [14] and dyes $[15,16]$. Graphene could be modified to adsorb pollutants via $\pi-\pi$, electrostatic interaction and hydrogen bonding. However, the cost of a carbon-based nano-adsorbent is high and the regeneration treatment of spent materials is often challenging [17]. Due to strong $\pi-\pi$ bonds and van der Waals forces, graphene sheets tend to condense and restack. CNTs often group into bundles and tangle due to the same reason. Therefore, the available specific surface area of these carbon nanomaterial is much lower than the theoretical value, greatly restricting their practical applications [18]. Thus, providing a recycling function and reducing the aggregation potential of the carbon nanomaterials are vital ways to design high-efficiency adsorbents.

Nanocelluloses are a class of renewable nanomaterials derived from the most abundant natural polymer on earth. Their high specific surface area, bioavailability and surface reactivity make nanocelluloses interesting materials for pollutant adsorbents [19]. Since unmodified nanocelluloses expose abundant surface hydroxyl groups and perhaps other negatively charged groups such as sulfate or carboxylate groups depending on the preparation procedure [20,21], they are well-suited for the adsorption of cationic molecules. Recently, high surface-area cellulose nanofibril (CNF) aerogels prepared via 2,2,6,6-tetramethylpyperidine-1-oxyl (TEMPO) oxidation were shown to absorb cationic malachite green $(\mathrm{MG})$ dye $\left(212.7 \mathrm{mg} \mathrm{g}^{-1}\right)$ due to electrostatic interactions between MG and negatively charged oxygen moieties on the CNF surface [22]. To make nanocellulose adsorbents for anionic dye, chemical modifications, such as introduction of positively charged amino groups, are usually required [23]. However, these positively charged nanocelluloses are no longer suitable for cationic dye adsorption.

While the above studies demonstrate the individual efficacy of carbon nanomaterials and nanocellulose adsorbents, improved adsorption performance and cost optimization may be realized by combining these nanomaterials together. Since carbon nanomaterials and nanocellulose exhibit different affinities for given molecules; hence, their combination can increase the variety of pollutants that may be adsorbed. Recently, CNFs were shown to improve the dispersion of carbon nanotubes $[24,25]$ and graphene [26] in aqueous solutions. Hajian et al. [26] suggested the charges on the TEMPO oxidized CNFs induced an electrostatic stabilization of the CNF-carbon nanomaterial complexes to prevent aggregation. When oxygen-containing carbon nanomaterials, such as graphene oxide (GO) or oxidized CNTs, were used, there was a strong interaction between the oxygen-containing groups of carbon nanomaterials and hydroxyl groups of nanocellulose [27]. Recently, Wei et al. [27] synthesized GO/microcrystalline cellulose (MCC) aerogels in an LiBr aqueous solution. Hybrid GO/MCC aerogel had higher adsorption capacity of MB per unit mass of GO $\left(2630 \mathrm{mg} \mathrm{g}^{-1}\right)$ than pure GO when the content of GO was low (0.3 wt\%). Hussain et al. [28] fabricated GO/CNF monoliths based on a urea-assisted self-assembly method. The maximum adsorption capacity of these hybrid monoliths to $\mathrm{MB}$ achieved $227.27 \mathrm{mg} \mathrm{g}^{-1}$. Wu et al. [29] exploited cellulose nanofiber as a cross-linker to interweave between reduced graphene oxide (rGO) layers and obtained hybridized monolith aerogels by a hydrothermal method. The hybridized monolith was able to adsorb not only hydrophilic dyes, 
but also hydrophobic organic oil. To our knowledge, the influence of carbon nanomaterials features, such as their morphology (nanotubes or nanoplates), on the adsorption behaviors of the CNF/carbon nanomaterial hybrids have not been explored.

Concerning industrial wastewater, different types of dyes could be found. Most of the previous works focus on single solute adsorption in pure water and are not representative of real-world wastewater effluents. During this study, two types of carbon nanomaterials, CNTs and graphene nanoplates (GnPs), are dispersed in water with CNFs using different mass ratios, respectively, to prepare hybrid aerogels through a simple freeze-drying procedure without the assistance of other agents. The aim is to understand the interactions of CNT and GnP with CNF and to explore the adsorption capacity of these hybrid materials to both anionic and cationic dyes in single and binary systems. The preparation, characterization, and adsorption assessments of CNF-CNT and CNF-GnP aerogels for $\mathrm{MB}$ and $\mathrm{CR}$ dyes are reported. Adsorption behaviors of dyes are inspected by kinetic models and adsorption isothermal models. The adsorption mechanism, contact time, and concentration of MB and CR dye to hybrid aerogels are investigated. Furthermore, desorption of both dyes from the adsorbents are studied.

\section{Materials and Methods}

\subsection{Materials}

Rice straw was harvested at the South China Agricultural University in 2016. Benzene $(99.5 \%$, AR, Damao Chemical Reagent Factory, Tianjin, China), ethanol (99.7\%, AR, Guangzhou Chemical Reagent Factory, Guangzhou, China), sodium chlorite $\left(\mathrm{NaClO}_{2}, 80 \%\right.$, Aladdin), acetic acid glacial $\left(\mathrm{CH}_{3} \mathrm{COOH}, 99.5 \%\right.$, AR, Guangzhou Chemical Reagent Factory), potassium hydroxide (KOH, 85\%, AR, Shanghai RichJoint Chemical Reagents, Shanghai, China), hydrochloric acid ( $\mathrm{HCl}, 1 \mathrm{~N}$, certified, Guangzhou Chemical Reagent Factory), sodium hydroxide (NaOH, 96\%, Guangzhou Chemical Reagent Factory), sodium hypochlorite (NaClO, 8.0\%, AR, Damao Chemical Reagent Factory), 2,2,6,6-tetramethylpyperdine-1-oxyl (TEMPO, 98\%, Aladdin), sodium bromide ( $\mathrm{NaBr}, 99.9 \%$, AR, Tianjin Fuchen Chemical Reagent Factory, Tianjin, China), methylene blue (MB, AR, Tianjin Fuchen Chemical Reagent Factory), Congo red (CR, Tianjin Fuchen Chemical Reagent Factory), graphene nanoplates (GnPs, Aldrich, grade C-750, thickness: a few nm, particle size: $<2 \mu \mathrm{m}$, specific surface area: $750 \mathrm{~m}^{2} \mathrm{~g}^{-1}$ ), and $\mathrm{OH}$-functionalized multi-walled carbon nanotubes (CNTs, Cheap Tubes, external diameter: $50-80 \mathrm{~nm}$, internal diameter: $5-10 \mathrm{~nm}$, length: $10-20 \mu \mathrm{m}, \mathrm{OH}$ content: $5.5 \%$, specific surface area: $60 \mathrm{~m}^{2} \mathrm{~g}^{-1}$ [30]) were used as received. The chemical formula, maximum absorption wavelength and electrical property under neutral $\mathrm{pH}$ of $\mathrm{MB}$ and $\mathrm{CR}$ are shown in Table S1. The deionized (DI) water used was purified by an AIKE Advanced-II-OS water purification system (Cheng Du Kangning Science and Technology Development Company, Chengdu, China).

\subsection{Preparation of Cellulose Nanofibrils}

Pure cellulose was prepared from rice straw by extracting wax and dissolving lignin, hemicellulose and silica [31]. Cellulose nanofibrils (CNFs) were prepared by TEMPO mediated oxidation employing $5 \mathrm{mmol} \mathrm{NaClO}$ per gram of cellulose followed by mechanical blending at 37,000 rpm for $30 \mathrm{~min}$ [32]. TEMPO-mediated oxidation converted the C6 primary hydroxyls on the surface of the cellulose into carboxyls [33]. The successive mechanical treatment disintegrated oxidized cellulose fibers into individual nanofibrils that were $1-5 \mathrm{~nm}$ in width and hundreds of nanometers to $2 \mu \mathrm{m}$ in length [32]. The carboxylate content of the CNF was measured using a conductometric titration (Oakton CON $6+$, Cole-Parmer Instrument Company, Vernon Hills, IL, USA) following a previous method (Gu and Hsieh, 2015) (Figure S1). The carboxylate $\left(\mathrm{COOH}+\mathrm{COO}^{-}\right)$content was determined to be $1.36 \mathrm{mmol} / \mathrm{g}$ at neutral $\mathrm{pH}(\mathrm{COOH}$ content: $0.137 \mathrm{mmol} / \mathrm{g})$. 


\subsection{Preparation of CNF, CNF-CNT and CNF-GnP Aerogels}

CNTs or GnPs were added to CNF dispersions with various mass ratios of CNF to carbon nanomaterial (1:0, 3:1, 1:1, 1:3 and 0:1). The final concentration of all the mixtures was controlled to be $6 \mathrm{mg} \mathrm{mL}{ }^{-1}$. The mixtures were sonicated by ultrasonic cell disruptor (SCIENTZ, IID, Ningbo, China) at $600 \mathrm{~W}$ for $30 \mathrm{~min}$ in an ice bath. Each sample was frozen at $-21^{\circ} \mathrm{C}$ for $4 \mathrm{~h}$ in a $15 \mathrm{~mL}$ polypropylene centrifuge tube followed by freeze-drying at $-50{ }^{\circ} \mathrm{C}$. The CNF-CNT and CNF-GnP hybrid aerogels were obtained. Pure CNF aerogel also was obtained via the same method from a CNF suspension of 6 $\mathrm{mg} \mathrm{mL} \mathrm{L}^{-1}$.

\subsection{Characterization}

The dispersion quality of aqueous $\mathrm{CNT} / \mathrm{CNF}$ and $\mathrm{GnP} / \mathrm{CNF}$ mixtures after sonication was examined by depositing a drop of each suspension on a glass slide for optical microscope observations. The size of the aggregates was measured and averaged over 150-200 particles. Regarding the compression test, the aerogel samples were transferred into a chamber with a temperature of $25 \pm 2{ }^{\circ} \mathrm{C}$ and a relative humidity of $65 \pm 2 \%$. The compressive strength of the samples was measured $24 \mathrm{~h}$ later with a compression ratio of $1 \mathrm{~mm} \mathrm{~min}^{-1}$ on a universal mechanical testing machine (CMT1000, SUST, Zhuhai, China). The morphology of CNF, CNF-CNT, CNF-GnP aerogels and CNT, GnP powder was obtained by a field emission scanning electron microscope (FE-SEM, SU-70, Hitachi, Chiyoda, Japan) after sputtering coating the samples with gold at $15 \mathrm{~mA}$ for $2 \mathrm{~min}$ under vacuum conditions (Hitachi, E-1010 Ion Sputtering System, Japan). Imaging of the samples was performed at 0.5-30 kV acceleration voltage and 1-2 nA current intensity at magnifications of 20-800,000 times. The chemical structures of $\mathrm{CNF}, \mathrm{CNF}-\mathrm{CNT}$, CNF-GnP aerogels and CNT, GnP powder were characterized by Fourier transform infrared spectroscopy (FTIR, PerkinElmer, Spectrum 100, Waltham, MA, USA) scanning from 4000 to $400 \mathrm{~cm}^{-1}$ with a resolution of $4 \mathrm{~cm}^{-1}$. Before FTIR measurements, $2 \mathrm{mg}$ dry sample was ground into powder with $200 \mathrm{mg} \mathrm{KBr}$ and pressed into pellets. The specific surface area (SSA) of the samples was calculated using Equation (1) [34].

$$
\mathrm{SSA}=\frac{N_{\mathrm{A}} A_{\mathrm{MB}}\left(C_{\mathrm{o}}-C_{\mathrm{e}}\right) V}{M_{\mathrm{MB}} M_{\mathrm{S}}}
$$

where $N_{\mathrm{A}}$ is Avogadro's number $\left(6.023 \times 10^{23} \mathrm{~mol}^{-1}\right), A_{\mathrm{MB}}$ is the covered area per MB molecules (typically assumed to be $1.35 \mathrm{~nm}^{2}$ ), $C_{\mathrm{o}}$ and $C_{\mathrm{e}}$ are the initial and equilibrium concentration of $\mathrm{MB}$, respectively, $V$ is the volume of the $\mathrm{MB}$ solution, $M_{\mathrm{MB}}$ is the relative molecular mass of $\mathrm{MB}$, and $M_{\mathrm{S}}$ is the mass of the sample.

\subsection{Adsorption of Dyes in Single Systems}

Anionic dye $\mathrm{CR}$ and cationic dye $\mathrm{MB}$ were used in the adsorption experiment. CNF, CNF-CNT, $\mathrm{CNF}-\mathrm{GnP}$ were aerogels, while pristine $\mathrm{CNT}$ and $\mathrm{GnP}$ were in the form of powder. Aqueous phase adsorption studies were conducted at $25^{\circ} \mathrm{C}$ by submerging $5 \mathrm{mg}$ of a specific nano adsorbent into $20 \mathrm{~mL}$ of each dye solution at neutral $\mathrm{pH}$. The mixture was continuously agitated on an orbital shaker at 120 rpm and the amount of residual dye in the solution was determined by ultraviolet-visible spectroscopy (UV-Vis, Thermo Scientific, Evolution 201, Waltham, MA, USA) at the maximum absorption wavelength using a measured extinction coefficient from a Beer's law analysis for each solution. The adsorption capacity of MB, CR on each adsorbent was calculated using Equation (2).

$$
q_{\mathrm{t}}=\frac{\left(C_{0}-C_{\mathrm{t}}\right) V}{m}
$$

where $q_{\mathrm{t}}$ is the amount of dye adsorbed at a given time $\left(\mathrm{mg} \mathrm{g}^{-1}\right), C_{0}$ is the initial dye concentration $\left(\mathrm{mg} \mathrm{L}^{-1}\right), C_{\mathrm{t}}$ is the residual dye concentration at a given time $\left(\mathrm{mg} \mathrm{L}^{-1}\right), V$ is the solution volume $(\mathrm{L})$, and $m$ is the mass of the adsorbent (mg). 
The effect of contact time (0-240 $\mathrm{min}$ ) was examined using $5 \mathrm{mg}$ of adsorbent and an initial dye concentration of 10, 250 and $500 \mathrm{mg} \mathrm{L}^{-1}$ for MB and 100, 600 and $2000 \mathrm{mg} \mathrm{L}^{-1}$ for CR. The effect of initial dye concentration on the final adsorption capacity was investigated in a range of dye concentrations (MB: 10, 50, 100, 150, 200, 250, 300, 400, 500, 600, 800 and $1000 \mathrm{mg} \mathrm{L}^{-1}$; CR: 10, 50, 100, 150, 200, 250, $300,400,500,600,800,1000,1500$ and $2000 \mathrm{mg} \mathrm{L}^{-1}$ ) using an adsorbent of $5 \mathrm{mg}$ at $25^{\circ} \mathrm{C}$ and $120 \mathrm{rpm}$ for $16 \mathrm{~h}$.

\subsection{Adsorption of Dyes in Binary Systems}

$\mathrm{MB}$ and CR were added into $20 \mathrm{~mL}$ DI water with various mass ratios at atal concentration of $200 \mathrm{mg} \mathrm{L}^{-1}$. The mass ratio of $\mathrm{MB}$ to $\mathrm{CR}$ was 3:1, 1:1 or 1:3. An adsorbent of $5 \mathrm{mg}$ was added, and the mixture was agitated at $25^{\circ} \mathrm{C}$ and $120 \mathrm{rpm}$ for $16 \mathrm{~h}$. Regarding a binary system, dye A (MB) and dye B (CR) concentrations were calculated as follows:

$$
\begin{gathered}
C_{\mathrm{A}}=\frac{k_{\mathrm{B} 2} d_{1}-k_{\mathrm{B} 1} d_{2}}{k_{\mathrm{A} 1} k_{\mathrm{B} 2}-k_{\mathrm{A} 2} k_{\mathrm{B} 1}} \\
C_{\mathrm{B}}=\frac{k_{\mathrm{A} 1} d_{2}-k_{\mathrm{A} 2} d_{1}}{k_{\mathrm{A} 1} k_{\mathrm{B} 2}-k_{\mathrm{A} 2} k_{\mathrm{B} 1}}
\end{gathered}
$$

where $d_{1}$ and $d_{2}$ are the mixture optical densities measured at $\lambda_{1}(664 \mathrm{~nm})$ and $\lambda_{2}(498 \mathrm{~nm})$, respectively. $k_{\mathrm{A} 1}, k_{\mathrm{B} 1}, k_{\mathrm{A} 2}$, and $k_{\mathrm{B} 2}$ are the calibration constants for components $\mathrm{A}$ and $\mathrm{B}$ at wavelengths of $\lambda_{1}$ and $\lambda_{2}$, respectively $[35,36]$.

\subsection{Desorption of Dyes}

Desorption of $\mathrm{MB}$ and $\mathrm{CR}$ from CNF, GnP and CNF-GnP 3:1 was performed in ethanol, acetonitrile, acetone or $400 \mathrm{mM} \mathrm{NaCl}$ at $25^{\circ} \mathrm{C}$. First, the adsorbents were added into $20 \mathrm{~mL}$ of $100 \mathrm{mg} \mathrm{L}^{-1}$ dye solutions for adsorption at $120 \mathrm{rpm}$ and then taken out from the dye solutions after $16 \mathrm{~h}$. These adsorbents were transferred to $20 \mathrm{~mL}$ of desorption agents. After $1 \mathrm{~h}$, the adsorbents were removed and the dye concentration in the solution was measured. The adsorbents might again have been transferred to a fresh desorption agent and the desorption step was repeated for several cycles. Dye percentage removal (\%) was calculated by Equation (5):

$$
\operatorname{Removal}(\%)=\frac{D_{\mathrm{t}}}{C_{0}-C_{\mathrm{e}}} \times 100
$$

where $D_{\mathrm{t}}$ is the concentration of dye in the desorption $\left(\mathrm{mg} \mathrm{L}^{-1}\right), C_{0}$ and $C_{\mathrm{e}}$ are the initial and final concentrations of dye in the adsorption $\left(\mathrm{mg} \mathrm{L}^{-1}\right)$, respectively.

\section{Results and Discussion}

\subsection{Effect of Adsorbent Structure}

Figure 1 shows the uptake of $\mathrm{MB}$ or $\mathrm{CR}$ after $16 \mathrm{~h}$ with constant agitation on different nanosorbents. The initial MB and CR concentrations were $500 \mathrm{mg} \mathrm{L}^{-1}$ and $2000 \mathrm{mg} \mathrm{L}^{-1}$, respectively. Pure CNF adsorbed the highest amount of cationic MB per unit mass (1207.2 $\left.\mathrm{mg} \mathrm{g}^{-1}\right)$ due to the large quantity of negatively charged carboxyl groups present on its surface. However, the amount of CR adsorbed on pure CNF was low (175.5 $\mathrm{mg} \mathrm{g}^{-1}$ ) possibly due to Coulombic repulsions between negatively charged CNF and anionic CR. Pure GnP powder $\left(1491.7 \mathrm{mg} \mathrm{g}^{-1}\right)$ was able to adsorb the highest amount of CR followed by pure CNT powder $\left(777.9 \mathrm{mg} \mathrm{g}^{-1}\right)$. The ability of $\mathrm{GnP}$ to remove MB was also superior to CNT, which can be attributed to the larger surface area of GnP with more sites available for adsorption. Compared to nanocellulose, carbon nanomaterials could adsorb both cationic and anionic dyes mainly though $\pi-\pi$ interaction [37]. Among the hybrid aerogels, CNF-GnP aerogels were generally better than CNF-CNT aerogels in the ability to remove both types of dyes from water at the same CNF to carbon 
nanomaterial ratio. Moreover, the adsorption capacity of MB onto CNF-GnP 3:1 (1166.1 $\left.\mathrm{mg} \mathrm{g}^{-1}\right)$ was very close to that of pure CNF. As the quantity of carbon nanomaterials in the hybrid increased, the MB uptake gradually decreased because CNF was displaced by nano adsorbents with lower affinity for MB. Interestingly, among all hybrid aerogels, CNF-GnP 3:1 also exhibited the highest CR uptake $\left(507.1 \mathrm{mg} \mathrm{g}^{-1}\right)$, almost two times greater than pure CNF. Similar results were obtained for CNF-CNT hybrids, with CNF-CNT 3:1 having superior MB and CR uptakes than other CNF-CNT combinations. This may suggest that high CNF concentrations can reduce carbon nanomaterial aggregation and improve dispersion quality to promote more effective contact between the solute and the sorbent. $t$-test results indicated the adsorption of MB onto CNF-GnP 3:1 and CNF-CNT 3:1 had no significant difference ( $p>0.01$ ), but CNF-GnP 3:1 was superior to CNF-CNT 3:1 in the adsorption of CR ( $p$ $<0.01$ ) (Tables S2-S5). Based on these observations, hybrid aerogels comprising a CNF to carbon nanomaterial ratio of 3:1 were selected for further dispersion, mechanics, morphology, and chemical structure analysis. The CNF-CNT 3:1 and CNF-GnP 3:1 sorbents are reported henceforth as CNF-CNT and $\mathrm{CNF}-\mathrm{GnP}$, respectively.
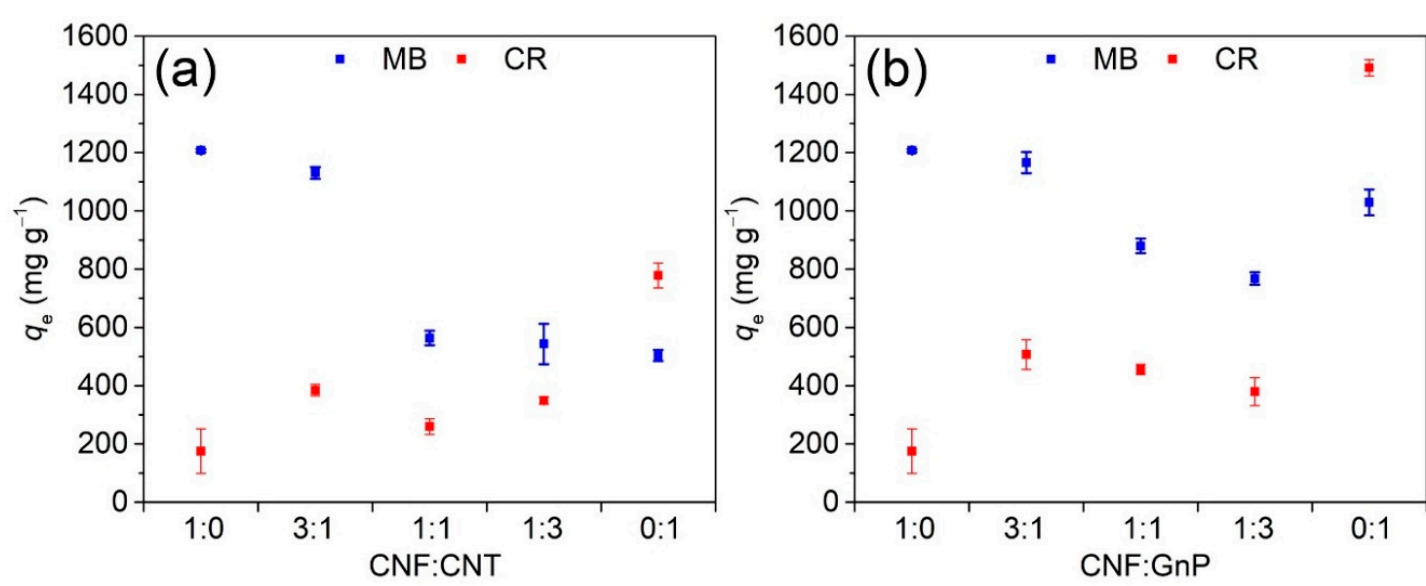

Figure 1. The final adsorption of $\mathrm{MB}$ and $\mathrm{CR}$ onto $\mathrm{CNF}-\mathrm{CNT}$ aerogels with the mass ratio of 1:0, 3:1, 1:1, 1:3 and 0:1 (a), CNF-GnP aerogels with the mass ratio of 1:0, 3:1, 1:1, 1:3 and 0:1 (b). Initial MB concentration was $500 \mathrm{mg} \mathrm{L}^{-1}$. Initial CR concentration was $2000 \mathrm{mg} \mathrm{L}^{-1}$.

The dispersion states of $\mathrm{CNT}$ and $\mathrm{GnP}$ aqueous suspensions in the presence of CNFs were investigated by optical microscopy after probe sonication for $5 \mathrm{~min}$ and $30 \mathrm{~min}$ (Figure S2). After $5 \mathrm{~min}$ of ultrasonic treatment, the average particle sizes of CNTs and GnPs were $8.8 \pm 13.1 \mu \mathrm{m}$ (Figure S2a) and $6.6 \pm 11.0 \mu \mathrm{m}$ (Figure S2c), respectively. After $30 \mathrm{~min}$ of ultrasonic treatment, large particle aggregations disappeared in each case (Figure S2b,d). The average particle sizes of CNTs and GnPs were $2.1 \pm 0.5 \mu \mathrm{m}$ and $3.1 \pm 0.9 \mu \mathrm{m}$, respectively. The hydrophobicity of carbon nanomaterials and their tendency to readily form aggregates by hexagonal packing of individual particles with high van der Waals binding energy can greatly reduce the surface area available for adsorption. Ultrasonication provided sufficient energy to break the aggregates of carbon nanomaterials. While TEMPO-oxidized CNFs had negatively charged surface carboxyls, the counterions on the surface of the CNFs induced dipoles in the $\mathrm{sp}^{2}$ carbon lattice of the carbon nanomaterials. Then, the charges on the CNFs induced electrostatic stabilization between $\mathrm{CNF}$ and $\mathrm{CNT} / \mathrm{GnP}$ that prevented the carbon nanomaterials from reaggregation [26]. Van der Waals interactions also may occur between CNF and CNT/GnP. CNTs contained few hydroxyl groups and were able to form hydrogen bonds with CNFs. The homogeneous $\mathrm{CNF} / \mathrm{CNT}$ and $\mathrm{CNF} / \mathrm{GnP}$ suspensions remained stable for at least $12 \mathrm{~h}$, which was long enough for the preparation of the hybrid aerogels.

Pure CNF aerogel was white with a porous external structure and turned black with the incorporation of carbon nanomaterials (Figure 2, inset). The aerogels formed inside centrifuge tubes during freeze-drying remained intact as cylindrical blocks and could be easily cut into slices using a 
sharp blade with no apparent deformation. The compression stress-strain curves of the three aerogels are shown in Figure 2. All curves exhibited "slow slope type" before the strain reached $80 \%$. The initial strength of CNF and CNF-GnP aerogels was similar and higher than that of CNF-CNT. After the strains reached $80 \%$, the curves were "steep type". Inflection points were observed when the strains were approximately $80 \%$. Under the strains of $80 \%$, the compression strengths of CNF, CNF-CNT and CNF-GnP were $0.064,0.014$ and $0.036 \mathrm{MPa}$, respectively. When immersed in water after compression testing, $\mathrm{CNF}, \mathrm{CNF}-\mathrm{CNT}$ and $\mathrm{CNF}-\mathrm{GnP}$ aerogels exhibited a water activated shape recovery property (Supplementary Movies S1-S3). The aerogels absorbed water and restored the deformation. Most of the water could be easily squeezed out with tweezers and the compact aerogels could reabsorb water and return to their original size and shape. The fact that the aerogel cylinders were easily squeezed to $\sim 10 \%$ of their length and quickly regained the same dimensions with a complete recovery, indicate that the aerogels were mechanically strong, and their open structure allowed the liquid solution to rapidly and freely flow in and out.

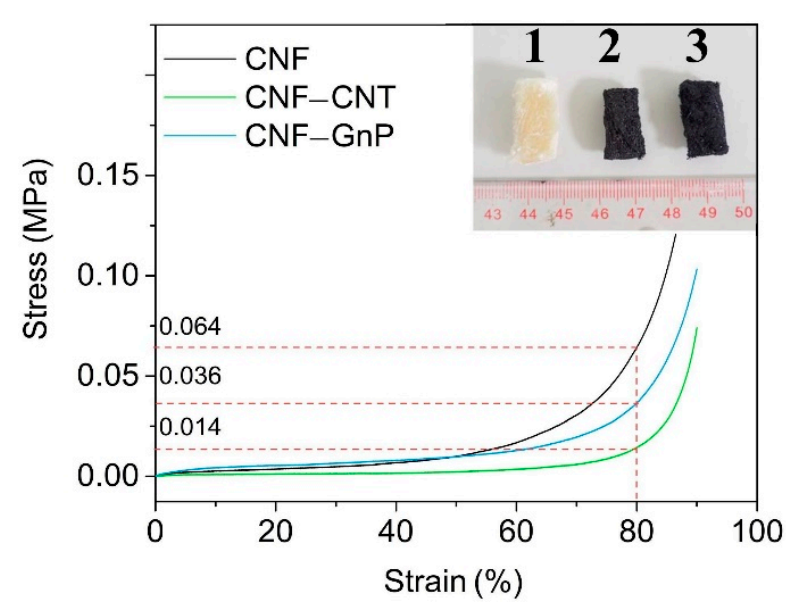

Figure 2. Stress-strain curves of $\mathrm{CNF}, \mathrm{CNF}-\mathrm{CNT}$ and $\mathrm{CNF}-\mathrm{GnP}$. The inset is a photograph of the freeze-dried aerogels. 1: CNF, 2: CNF-GnP and 3: CNF-CNT.

The morphologies of the CNF, CNT, GnP, CNF-CNT and CNF-GnP adsorbents have been characterized by SEM (Figure 3a-h). Pure CNF aerogel exhibited a three-dimensional structure with an intercalation of flat and folded sheets and contained pores of various shapes, which may be ascribed to the high suspension concentration (i.e., $6 \mathrm{mg} \mathrm{mL}^{-1}$ ) used before freeze-drying. Pristine CNT and $\mathrm{GnP}$ powders revealed the presence of bundles and stacked aggregates due to strong attractive forces between individual particles (Figure 3c,d). The combination between CNT and CNF affected the formation of the CNF sheet structure (Figure 3e). This is the reason that CNF-CNT aerogel produces debris after compression performance testing (Supplementary Movie 2). CNT dispersed better in the CNF matrix (Figure 3f). However, at higher magnification (Figure 3f, inset), some CNT aggregates could be observed still in the matrix. Since both CNFs and CNTs were anisotropic rods, and CNTs were much longer than $\mathrm{CNFs}$, individual CNT partly uncovered by CNFs may re-associate with each other during the freeze-drying process. Thus, the CNT surface active sites available for dye adsorption were reduced. $\mathrm{CNF}-\mathrm{GnP}$ formed porous aerogels with the main framework still being composed of CNF, while granular GnPs were evenly distributed in the CNFs matrix after ultrasonication and freeze-drying (Figure 3g,h). This can be attributed to the strong interactions between CNF and GnP, preventing GnP stacking and improving the hydrophilicity of GnPs [38]. The graphene platelets were well separated by rod-like CNFs. To contrast with the irregular and aggregated structure of CNT and GnP powders, the hybrid aerogels exhibited an open pore network that can facilitate fast molecular diffusion, hence promoting the accessibility of adsorption sites to relatively large dye molecules. Noteworthy, the morphology of CNF-GnP aerogels was quite different from the curly morphology of pure graphene aerogel in a previous study [39]. 

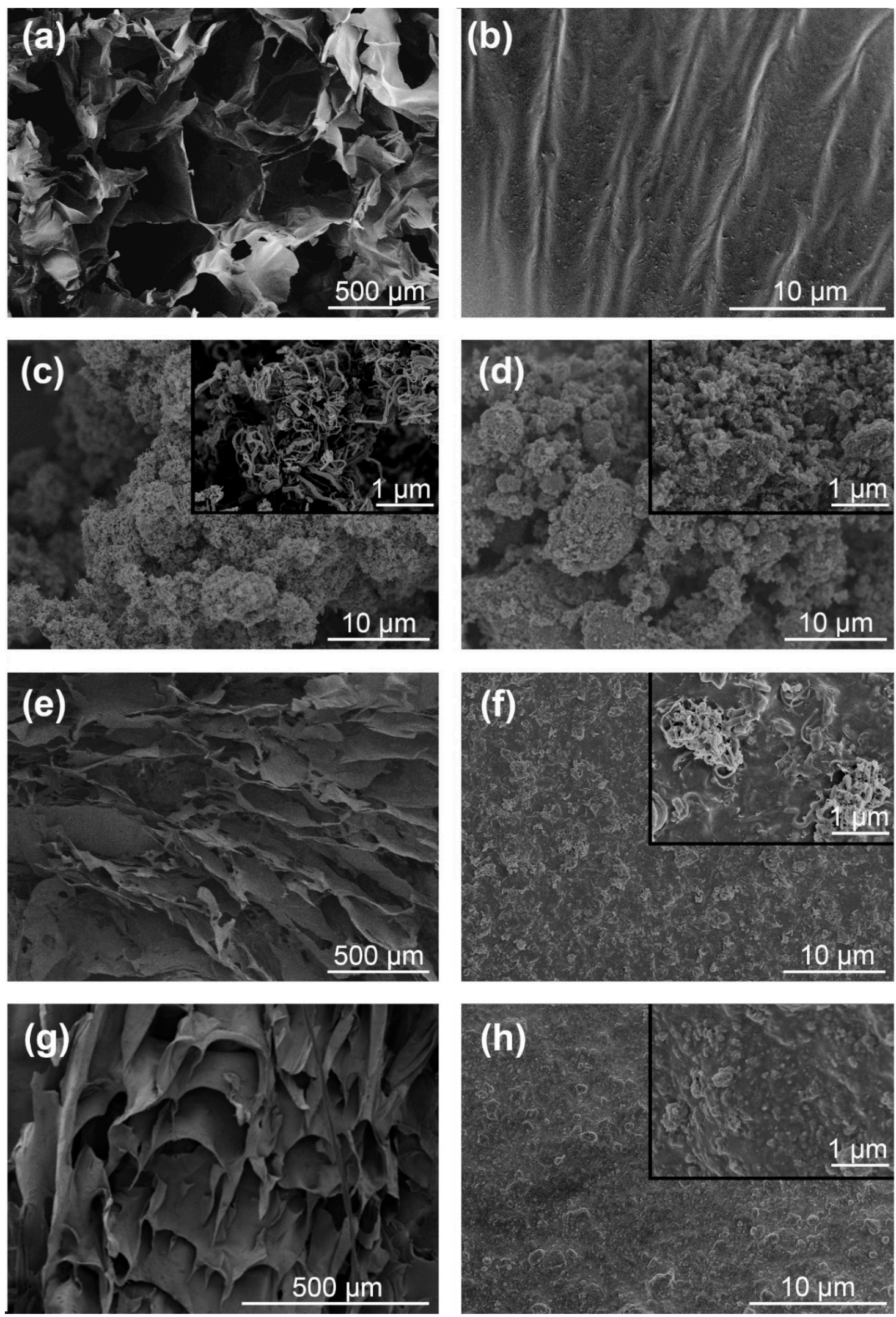

Figure 3. FE-SEM images of CNF aerogel (a,b), CNT (c), GnP (d), CNF-CNT aerogel (e,f) and CNF-GnP aerogel $(\mathbf{g}, \mathbf{h})$. The insets in $(\mathbf{c}, \mathbf{d}, \mathbf{f}, \mathbf{h})$ are FE-SEM images of CNT, GnP, CNF-CNT and CNF-GnP at a high magnification, respectively. 
The FTIR spectra of CNF, CNF-CNT, CNF-GnP, CNT and GnP are shown in Figure 4. The CNF spectrum showed common cellulose peaks: broad hydroxyl stretching at $3360 \mathrm{~cm}^{-1}$ and bending at $1610 \mathrm{~cm}^{-1}$, predominant $\mathrm{C}-\mathrm{O}$ peaks at 1168,1112 , and $1062 \mathrm{~cm}^{-1}$, and a C-H stretching peak at 2900 $\mathrm{cm}^{-1}$, respectively. The small shoulder at $1712 \mathrm{~cm}^{-1}$ was associated with the carbonyl stretching of the carboxylic acid, confirming C6 primary hydroxyl conversion to carboxyls from TEMPO oxidation [21]. The CNT and GnP spectra were nearly featureless. A small bump at $1570 \mathrm{~cm}^{-1}$ was assigned to $\mathrm{C}=\mathrm{C}$ groups in graphene. Bending vibrations of $\mathrm{C}-\mathrm{O}-\mathrm{C}$ at $1210 \mathrm{~cm}^{-1}$ and $\mathrm{C}-\mathrm{O}$ at $1038 \mathrm{~cm}^{-1}$, respectively, indicated epoxide or $\mathrm{C}-\mathrm{OH}$ structure existing in $\mathrm{CNT}$ and graphene. These weak vibration peaks confirmed that the degree of oxidation in CNT and $\mathrm{GnP}$ were low. The cellulose characteristic peaks also were observed in the hybrid aerogels containing 25\% CNT/GnP. The change of wavenumber for $\mathrm{O}-\mathrm{H}$ in the hybrids indicated the existence of hydrogen bonding between CNT/GnP and CNF [40]. Since CNT and GnP only had few oxygen containing groups, van der Waals forces and, perhaps, hydrophobic interactions also contributed to the combination of the carbon nanomaterials and CNFs.

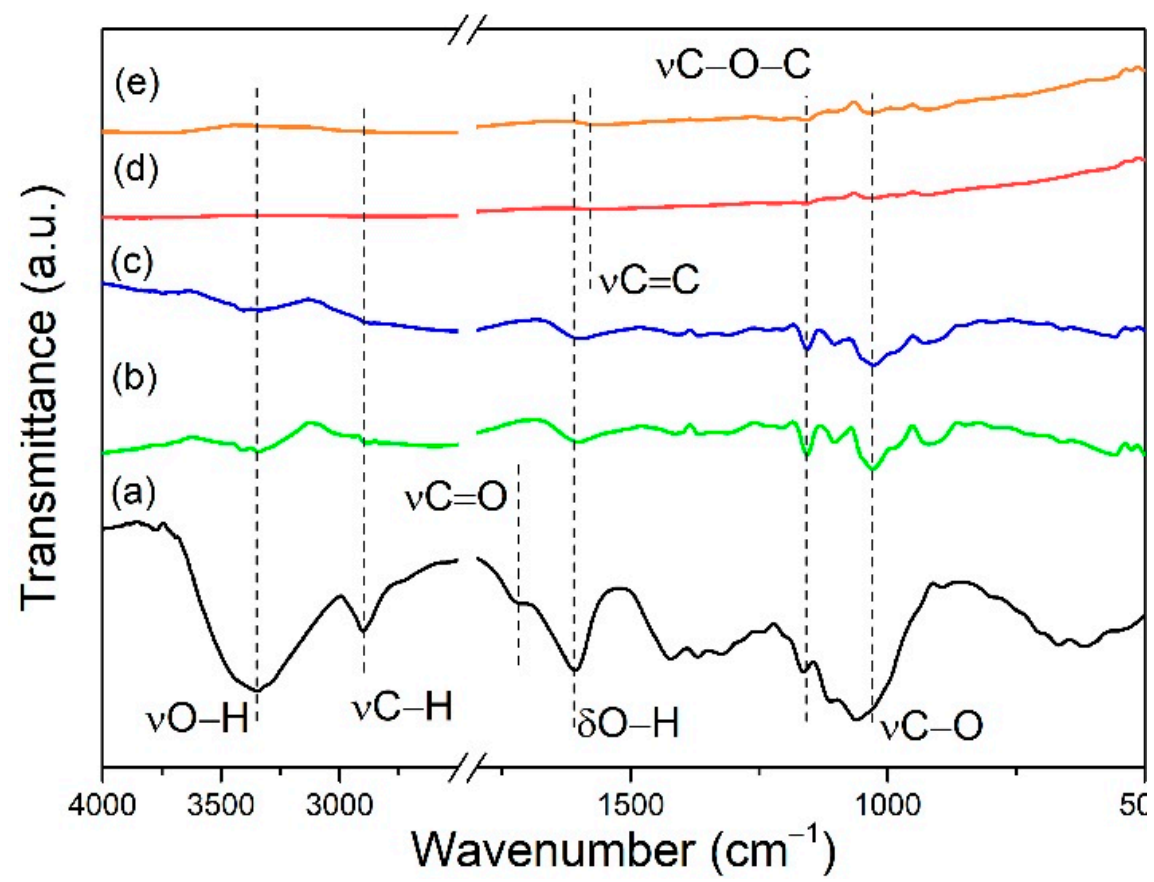

Figure 4. FTIR spectra of CNF (a), CNF-CNT (b), CNF-GnP (c), CNT (d) and GnP (e). To optimize the representation, the region of $2500-1800 \mathrm{~cm}^{-1}$ is omitted.

Based on adsorption, dispersion, mechanics, morphology and IR results mentioned above, the best performance of the CNF-GnP 3:1 hybrid aerogel perhaps resulted from the plate structure and large surface area of GnPs (i.e., The specific surface areas of $\mathrm{GnP}$ and $\mathrm{CNT}$ were 750 and $60 \mathrm{~m}^{2}$, respectively). A sufficient amount of CNFs prevented GnPs from stacking and improved the hydrophilicity of GnPs. However, CNTs still tangled with each other in the CNF matrix. Dye molecules adsorbed to the GnP portion mainly through $\pi-\pi$ and hydrophobic interactions, while cationic MB was able to adsorb to the negatively charged CNF portion by electrostatic interactions. Thus, CNF-GnP 3:1 aerogel was selected for future adsorption kinetics and isothermal modeling.

\subsection{Effect of Contact Time and Adsorption Kinetics}

The effect of CNF, CNF-GnP and GnP contact time $\left(25^{\circ} \mathrm{C}, 120 \mathrm{rpm}\right)$ on dye removal was studied at low, medium and high initial dye concentrations (Figure 5). The initial MB concentrations were 10, 250 and $500 \mathrm{mg} \mathrm{L}^{-1}$ and the initial CR concentrations were 10, 600 and $2000 \mathrm{mg} \mathrm{L}^{-1}$. The adsorption of $\mathrm{MB}$ dye onto $\mathrm{CNF}, \mathrm{CNF}-\mathrm{GnP}$ and $\mathrm{GnP}$ occurred rapidly during the first $30 \mathrm{~min}$, then leveled beyond 
60 min at all initial MB dye concentrations. The adsorption of CR dye onto CNF, CNF-GnP and GnP occurred at a lower speed compared to that of MB. The adsorption onto CNF and CNF-GnP slowed with adsorption time and reached a plateau beyond $90 \mathrm{~min}$ at all initial CR concentrations. However, the adsorption onto GnP still increased very slowly even after $120 \mathrm{~min}$ at all initial CR concentrations.
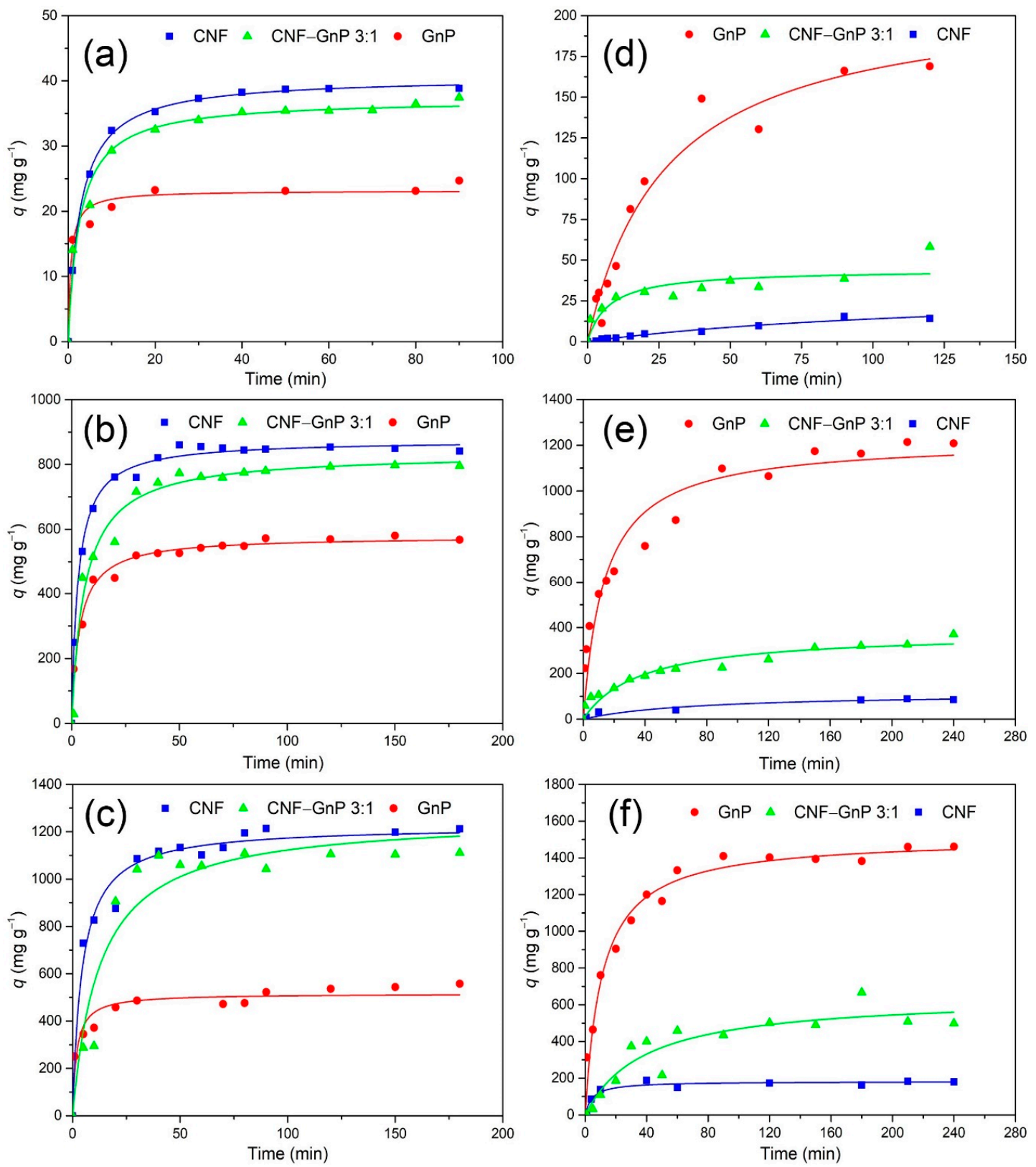

Figure 5. Effects of contact time on the dye removal efficiencies of $\mathrm{MB}$ and $\mathrm{CR}$ using CNF, CNF-GnP and GnP. Initial MB dye concentration: $10 \mathrm{mg} \mathrm{L}^{-1}$ (a), $250 \mathrm{mg} \mathrm{L}^{-1}$ (b), $500 \mathrm{mg} \mathrm{L}^{-1}$ (c). Initial CR concentration: $100 \mathrm{mg} \mathrm{L}^{-1}$ (d), $600 \mathrm{mg} \mathrm{L}^{-1}$ (e), $2000 \mathrm{mg} \mathrm{L}^{-1}$ (f). Pseudo-second-order adsorption kinetics was applied for all conditions in $(\mathbf{a}-\mathbf{f})$.

Adsorption kinetics models can be employed to predict the equilibrium adsorption capacity and elucidate the adsorption mechanism. During the adsorption process, the dye molecules migrated from the aqueous solution onto the surface of the adsorbent. MB molecules were adsorbed through electrostatic interactions. The electrostatic interactions occurred when the cationic dye MB was close enough to the adsorption sites $\left(-\mathrm{COO}^{-},-\mathrm{OH}\right)$ on the adsorbent surface. $\mathrm{CR}$ molecules were adsorbed mainly through $\pi-\pi$ bonding and hydrophobic interactions with carbon nanomaterials. 
Accompanying the increase in contact time, the accumulation of dye molecules on the adsorbent surface gradually increased and eventually reached equilibrium. The adsorption kinetics of $\mathrm{MB}$ and $\mathrm{CR}$ on different absorbents was evaluated using both the Lagergren's pseudo-first-order and the Ho's pseudo-second-order models. The Lagergren's pseudo-first-order kinetics is expressed as Equation (6) [41]:

$$
q_{\mathrm{t}}=q_{e}\left(1-e^{-k_{1} t}\right)
$$

where $k_{1}$ is the rate constant $\left(\mathrm{min}^{-1}\right), q_{\mathrm{t}}$ is the amounts of dye absorbed at a given time $\left(\mathrm{mg} \mathrm{g}^{-1}\right)$, and $q_{\mathrm{e}}$ is the amount of dye adsorbed at equilibrium $\left(\mathrm{mg} \mathrm{g}^{-1}\right)$. Nonlinear regression analysis was used to assess the values of $q_{\mathrm{e}}, k_{1}$. The Ho's pseudo-second-order kinetics was expressed as Equation (7) [42]:

$$
q_{\mathrm{t}}=\frac{q_{\mathrm{e}}^{2} k_{2} t}{1+q_{\mathrm{e}} k_{2} t}
$$

where $k_{2}$ is the pseudo-second-order rate constant $\left(\mathrm{g} \mathrm{mg}^{-1} \mathrm{~min}^{-1}\right)$. Nonlinear regression analysis was used to assess the values of $q_{\mathrm{e}}, k_{2}$. The initial adsorption rate $v_{0}$ at $t=0$ could be calculated using Equation (8):

$$
v_{0}=k_{2} \times q_{\mathrm{e}^{2}}^{2}
$$

Regarding all adsorbents, the pseudo-second-order model was generally more applicable for describing the adsorption of $\mathrm{MB}$, as demonstrated by the higher correlation coefficients $\left(R^{2}\right)$, compared to the first-order kinetics (Table 1). This result was consistent with previous reports of cationic dyes adsorbed onto pure CNF [22] and pure graphene [43]. The initial MB adsorption rate $\left(v_{0}\right)$ and MB dye adsorption capacity $\left(q_{\mathrm{e}}\right)$ increased rapidly with increasing original dye concentrations from 10 to $250 \mathrm{mg} \mathrm{L}^{-1}$ for all adsorbents. Further increasing of the original MB concentration from $250 \mathrm{mg}$ $\mathrm{L}^{-1}$ to $500 \mathrm{mg} \mathrm{L}^{-1}$ resulted in an increase of $v_{0}$ for pure $\mathrm{GnP}$, while $v_{0}$ did not change significantly in the cases of pure CNF and CNF-GnP hybrid. This phenomenon may be attributed to the limited amount of negatively charged adsorption sites on the CNF surface at longer contact times and higher $\mathrm{MB}$ concentrations. Although the adsorption of MB onto CNF-GnP sorbent was relatively slower than that on each component alone, the hybrid aerogel exhibited the highest theoretical MB adsorption capacity $\left(q_{\mathrm{e}}=1264.5 \mathrm{mg} \mathrm{g}^{-1}\right)$ at a high initial MB concentration (i.e., $\left.500 \mathrm{mg} \mathrm{L}^{-1}\right)$.

The pseudo-second order kinetic model was also clearly a better fit for the adsorption of CR onto pure GnP, which is consistent with a previous study [44]. However, the sorption of CR onto pure CNF could be described as either pseudo first-order kinetics or pseudo second-order kinetics, as indicated by the similar $R^{2}(0.94-0.98)$ for both models. Occurring at neutral $\mathrm{pH}$, both $\mathrm{CR}$ and $\mathrm{CNF}$ were negatively charged. Adsorption of $\mathrm{CR}$ onto $\mathrm{CNF}$ was relatively low and possibly resulted from hydrophobic interaction. The adsorption of CR onto the CNF-GnP hybrid also could be represented by either the first-order or second-order model and exhibited much higher uptake values than pure CNF. This result possibly indicates that in the hybrid material, CNF did not significantly affect the adsorption kinetics of $\mathrm{GnP}$, even though the $\mathrm{GnP}$ content was relatively small. Both the $\mathrm{CR}$ adsorption rate $\left(v_{0}\right)$ and $\mathrm{CR}$ adsorption capacity $\left(q_{\mathrm{e}}\right)$ increased with increasing the initial dye concentrations from 100 to $2000 \mathrm{mg}$ $\mathrm{L}^{-1}$ for all adsorbents. The augmentation of the initial concentration provided a greater driving force for the mass transfer and subsequent adsorption on the nanomaterials [45]. The theoretical $q_{\mathrm{e}}$ value for CNF-GnP reached $648.5 \mathrm{mg} \mathrm{g}^{-1}$ at a high initial CR concentration, 2.5 times higher than pristine CNF (182.4 $\left.\mathrm{mg} \mathrm{g}^{-1}\right)$. 
Table 1. Estimated kinetic parameters of the two adsorption models for methylene blue (MB) and Congo red (CR).

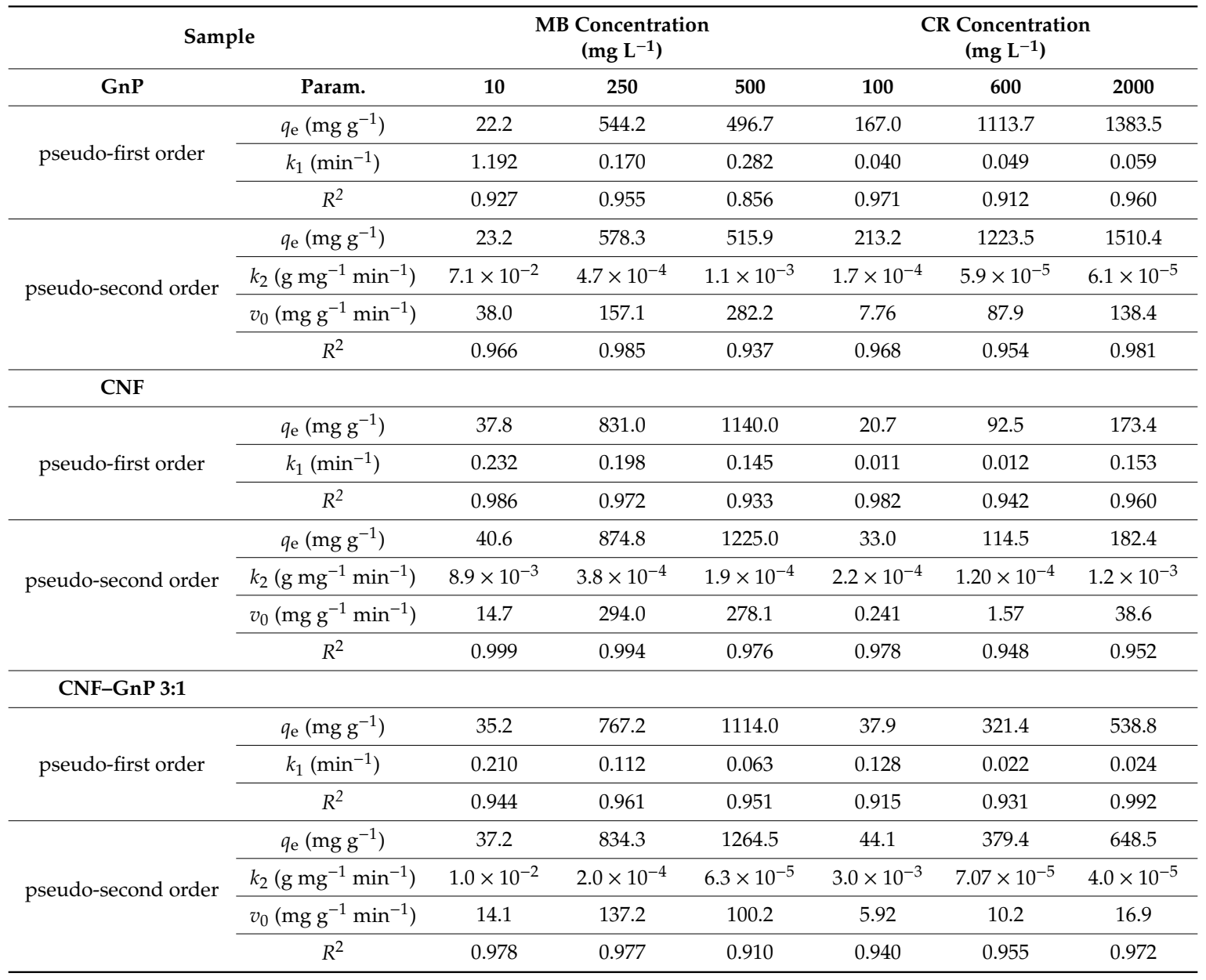

\subsection{Effect of Initial Dye Concentration and Adsorption Isotherm}

The effect of initial dye concentration on the adsorption capacity was investigated in the 10-1000 $\mathrm{mg} \mathrm{L}^{-1}$ and 10-2000 $\mathrm{mg} \mathrm{L}^{-1}$ ranges for $\mathrm{MB}$ and $\mathrm{CR}$, respectively. The systems were mixed at $25^{\circ} \mathrm{C}$ and $120 \mathrm{rpm}$ for $16 \mathrm{~h}$ and equilibrium was declared when there was no appreciable change in solution concentration with additional contact time. Concerning all adsorbents, at low dye concentration, adsorption increased dramatically with increasing concentration (Figure 6). The adsorption of $\mathrm{MB}$ reached a plateau when residual $\mathrm{MB}$ concentration was above $200 \mathrm{mg} \mathrm{L}^{-1}$ in all cases. The final MB adsorption at equilibrium for CNF-GnP was $1207.5 \mathrm{mg} \mathrm{g}^{-1}$ at the initial MB concentration of $1000 \mathrm{mg} \mathrm{L}^{-1}$. The adsorption of CR increased relatively slowly when the residual CR concentration was above $400 \mathrm{mg} \mathrm{L}^{-1}$ in all cases. The final CR adsorption at equilibrium of CNF-GnP was $507.1 \mathrm{mg} \mathrm{g}^{-1}$ at the initial CR concentration of $2000 \mathrm{mg} \mathrm{L}^{-1}$.

To further understand the mechanism of adsorption, the adsorbed quantities and residual dyes in the solution at equilibrium were fitted with isothermal models. The adsorption isotherm models describe the interaction between the adsorbate and adsorbent. Three models, Langmuir, Freundlich and Sips, were used to obtain the isotherm parameters for adsorption of dyes onto CNF, GnP, CNF-GnP.

The Langmuir isotherm equation is expressed as follows [46]:

$$
q_{\mathrm{e}}=\frac{q_{\mathrm{max}} K_{\mathrm{L}} C_{\mathrm{e}}}{1+K_{\mathrm{L}} C_{\mathrm{e}}}
$$


where $q_{\mathrm{e}}$ is the equilibrium adsorption amount per unit weight of the adsorbent $\left(\mathrm{mg} \mathrm{g}^{-1}\right), C_{\mathrm{e}}$ is the equilibrium concentration of adsorbate in the solution $\left(\mathrm{mg} \mathrm{L}^{-1}\right), q_{\max }$ is the maximum amount of the dyes adsorbed per unit weight of the adsorbent $\left(\mathrm{mg} \mathrm{g}^{-1}\right)$, which describes the complete single-layer coverage on the surface of the dye at a high equilibrium concentration of dyes, and $K_{\mathrm{L}}$ is the Langmuir adsorption equilibrium constant related to binding site affinity $\left(\mathrm{L} \mathrm{g}^{-1}\right)$, representing the bonding energy of adsorbent and adsorption product. The Langmuir isotherm model is based on the monolayer sorption on a surface with a finite number of identical sites and uniform adsorption energies.
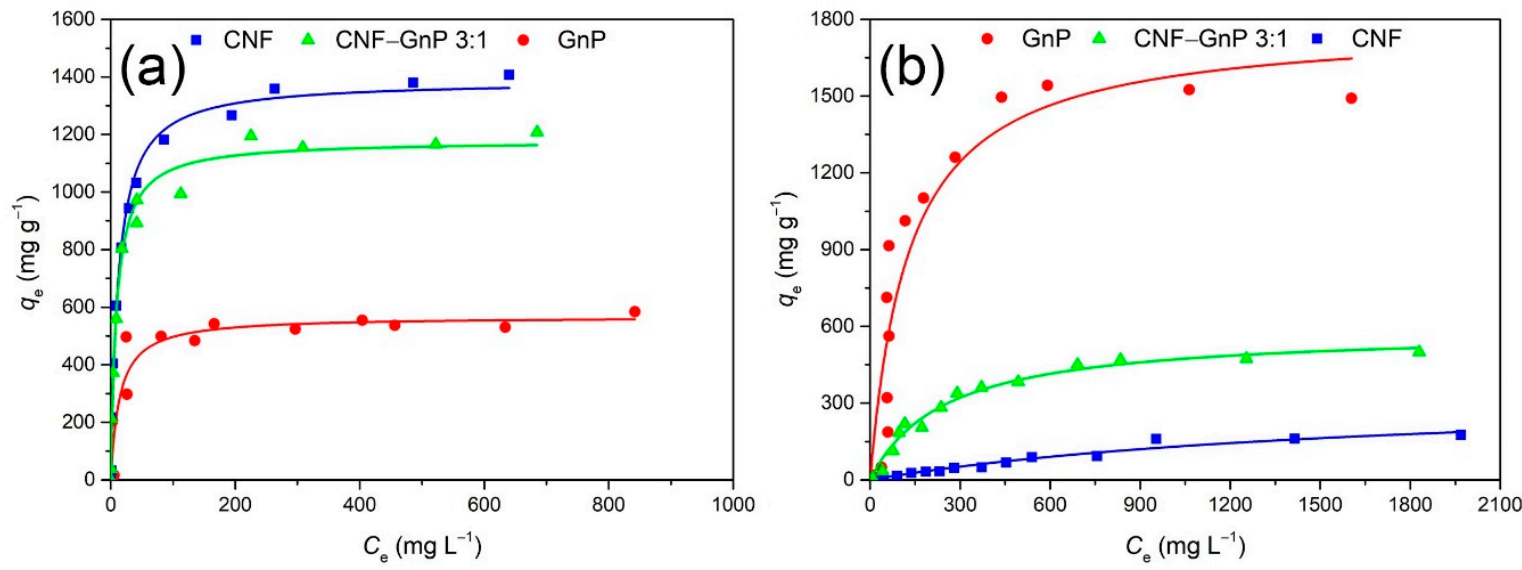

Figure 6. Adsorption of $\mathrm{MB}(\mathbf{a})$ and $\mathrm{CR}(\mathbf{b})$ to $\mathrm{CNF}, \mathrm{CNF}-\mathrm{GnP}$ and $\mathrm{GnP}$. The Langmuir adsorption model was applied for data fitting.

The Freundlich isotherm equation is expressed as below [47]:

$$
q_{\mathrm{e}}=K_{\mathrm{F}} \times C_{\mathrm{e}}^{\frac{1}{n}}
$$

where $K_{\mathrm{F}}\left(\mathrm{mg} \mathrm{g}^{-1}\right)$ and $\mathrm{n}$ are the Freundlich constants. The Freundlich isotherm model is an empirical equation for understanding the adsorption of heterogeneous surfaces with multiple adsorption layers. $K_{\mathrm{F}}$ and $\mathrm{n}$ are related to adsorption capacity, adsorption strength and spontaneity, respectively. When the value of $n$ is within the range of $1<n<10$, it indicates a good adsorption process. The larger $n$ value, the better the adsorption effect.

The Sips isotherm equation is given as follows [48]:

$$
\frac{1}{q_{\mathrm{e}}}=\frac{1}{q_{\max } K_{\mathrm{s}}}\left(\frac{1}{C_{\mathrm{e}}}\right)^{\frac{1}{n}}+\frac{1}{q_{\max }}
$$

where $q_{\max }$ is the Sips constant related to maximum adsorption capacity $\left(\mathrm{mg} \mathrm{g}^{-1}\right), K_{\mathrm{S}}$ is the isotherm constant of Sips related to adsorption energy $\left(\mathrm{L} \mathrm{g}^{-1}\right)$, and $n$ is the heterogeneity factor. The Sips model is a combination of the Langmuir and Freundlich isotherms. As $K_{\mathrm{S}}$ approaches 0, the Sips isotherm equation follows the Freundlich model. When $n$ approaches or equals 1, the Sips isotherm equation is reduced to the Langmuir isotherm.

The fitting parameters of each model are listed in Table 2. According to the correlation coefficients $\left(R^{2}\right)$, both the Langmuir and Sips adsorption models could adequately describe the dye adsorption on each adsorbent, while the Freundlich isotherm model was the least suitable. Since the Sips model is derived from the Langmuir equation, employs one more fitting parameter, and yields similar correlation coefficients, it could be concluded that the Langmuir model is more appropriate to describe the adsorption behavior. The Langmuir fitting curves for the adsorption of MB and CR on the different adsorbents are shown in Figure 6 . The binding constant $K_{\mathrm{L}}$ is related to the adsorption energy between the adsorbent and the dye. MB displayed higher binding constants (GnP: $7.0 \times 10^{-2} \mathrm{~L} \mathrm{~g}^{-1}$, CNF: 8.3 $\left.\times 10^{-2} \mathrm{~L} \mathrm{~g}^{-1}, \mathrm{CNF}-\mathrm{GnP}: 1.1 \times 10^{-1} \mathrm{~L} \mathrm{~g}^{-1}\right)$ than CR $\left(\mathrm{GnP}: 7.1 \times 10^{-3} \mathrm{~L} \mathrm{~g}^{-1}, \mathrm{CNF}: 8.6 \times 10^{-4} \mathrm{~L} \mathrm{~g}^{-1}\right.$, 
CNF-GnP: $3.8 \times 10^{-3} \mathrm{~L} \mathrm{~g}^{-1}$ ) regardless of the adsorbent nature, indicating a higher binding affinity to MB. Compared to the other dye-adsorbent complexes, the uptake of MB on CNF-GnP was the most favorable. The Langmuir model revealed that both $\mathrm{MB}$ and $\mathrm{CR}$ adsorbed as a monolayer on the CNF-GnP surfaces, with maximum adsorption capacities of $1178.5 \mathrm{mg} \mathrm{g}^{-1}$ and $585.3 \mathrm{mg} \mathrm{g}^{-1}$, respectively. According to Equation (1) and the monolayer adsorption, the specific surface areas (SSA) of CNF and CNF-GnP were determined to be 3220.4 and $3036.1 \mathrm{~m}^{2} \mathrm{~g}^{-1}$, respectively. Theoretically, if $\mathrm{CNF}$ is assumed to be a perfect cylinder with a $1 \mathrm{~nm}$ diameter (cellulose density: $1.5 \mathrm{~g} / \mathrm{cm}^{3}$ ), the surface area of CNF is $2667 \mathrm{~m}^{2} / \mathrm{g}$. The high SSA determined by MB adsorption indicates CNFs contained a large number of micropores.

Table 2. Estimated adsorption parameters of Langmuir, Freundlich and Sips isotherms at room temperature.

\begin{tabular}{|c|c|c|c|c|c|c|c|}
\hline \multicolumn{2}{|c|}{ Langmuir Adsorption Model } & \multicolumn{2}{|c|}{ GnP } & \multicolumn{2}{|c|}{ CNF } & \multicolumn{2}{|c|}{ CNF-GnP 3:1 } \\
\hline & & MB & CR & MB & CR & MB & CR \\
\hline \multirow{3}{*}{$q_{\mathrm{e}}=\left(q_{\max } K_{\mathrm{L}} C_{\mathrm{e}}\right) /\left(1+K_{\mathrm{L}} C_{\mathrm{e}}\right)$} & $q_{\max }\left(\mathrm{mg} \mathrm{g}^{-1}\right)$ & 567.1 & 1787.3 & 1387.2 & 351.7 & 1178.5 & 585.3 \\
\hline & $K_{\mathrm{L}}\left(\mathrm{Lg}^{-1}\right)$ & $7.0 \times 10^{-2}$ & $7.1 \times 10^{-3}$ & $8.3 \times 10^{-2}$ & $8.6 \times 10^{-4}$ & $1.1 \times 10^{-1}$ & $3.8 \times 10^{-3}$ \\
\hline & $R^{2}$ & 0.879 & 0.858 & 0.984 & 0.960 & 0.985 & 0.980 \\
\hline \multirow{2}{*}{\multicolumn{2}{|c|}{ Freundlich adsorption model }} & \multicolumn{2}{|c|}{ GnP } & \multicolumn{2}{|c|}{ CNF } & \multicolumn{2}{|c|}{ CNF-GnP 3:1 } \\
\hline & & MB & CR & MB & CR & MB & CR \\
\hline \multirow{3}{*}{$q_{\mathrm{e}}=K_{\mathrm{F}} \times C_{\mathrm{e}}^{1 / n}$} & $n$ & 5.431 & 2.995 & 4.512 & 1.428 & 4.984 & 1.944 \\
\hline & $K_{\mathrm{F}}\left(\mathrm{mg} \mathrm{g}^{-1}\right)$ & 181.3 & 156.1 & 376.5 & 0.966 & 364.2 & 29.9 \\
\hline & $R^{2}$ & 0.773 & 0.719 & 0.902 & 0.935 & 0.892 & 0.864 \\
\hline \multirow{2}{*}{\multicolumn{2}{|c|}{ Sips adsorption model }} & \multicolumn{2}{|c|}{ GnP } & \multicolumn{2}{|c|}{ CNF } & \multicolumn{2}{|c|}{ CNF-GnP 3:1 } \\
\hline & & MB & CR & MB & CR & MB & CR \\
\hline \multirow{4}{*}{$1 / q_{\mathrm{e}}=\left(1 / q_{\max } K_{\mathrm{s}}\right) \times\left(1 / C_{\mathrm{e}}\right)^{1 / n}+\left(1 / q_{\max }\right)$} & $q_{\max }\left(\mathrm{mg} \mathrm{g}^{-1}\right)$ & 552.4 & 1515.0 & 1453.0 & 235.2 & 1231.1 & 517.9 \\
\hline & $K_{\mathrm{s}}\left(\mathrm{Lg}^{-1}\right)$ & $4.1 \times 10^{-2}$ & $2.3 \times 10^{-4}$ & $1.2 \times 10^{-1}$ & $1.0 \times 10^{-4}$ & $1.5 \times 10^{-1}$ & $6.8 \times 10^{-4}$ \\
\hline & $n$ & 0.819 & 0.534 & 1.222 & 0.727 & 1.243 & 0.723 \\
\hline & $R^{2}$ & 0.869 & 0.885 & 0.991 & 0.960 & 0.988 & 0.969 \\
\hline
\end{tabular}

Extensive research about the uptake of various dyes on carbon-based and cellulose/polysaccharide-based composites has been reported in the literature. Table 3 presents a comparison of the maximum dye adsorption capacity of different adsorbents. CNF-GnP was able to adsorb both cationic MB and anionic $\mathrm{CR}$ and yielded higher uptake values compared to recent studies using cellulose, activated carbon, graphene, and CNT-based composites.

Table 3. Comparison of adsorption capacity of different adsorbents.

\begin{tabular}{|c|c|c|c|c|c|}
\hline Adsorbent & $\underset{\left(\mathrm{mg}^{-1}\right) \mathrm{MB}}{q_{\max }}$ & Ref. & Adsorbent & $\underset{\left(\mathrm{mg} \mathrm{g}^{-1}\right) \mathrm{CR}}{q_{\max }}$ & Ref. \\
\hline CNF-GnP aerogel & 1178.5 & this study & CNF-GnP aerogel & 585.3 & this study \\
\hline $\begin{array}{l}\text { Zeolite-activated carbon } \\
\text { composite from oil palm ash }\end{array}$ & 285.71 & [49] & $\begin{array}{l}\text { Polyaniline@GO-multiwalled } \\
\text { carbon nanotube } \\
\text { nanocomposite }\end{array}$ & 66.67 & [44] \\
\hline $\begin{array}{l}\text { Nickel nanoparticles/porous } \\
\text { carbon—carbon nanotube } \\
\text { hybrids }\end{array}$ & 312 & [50] & $\begin{array}{l}\text { Chitosan hydrogel beads } \\
\text { impregnated with CNT }\end{array}$ & 450.4 & [51] \\
\hline 3D rGO/L-Cys hydrogel & 660 & [52] & $\begin{array}{l}\text { Functionalized multiwalled } \\
\text { carbon nanotubes }\end{array}$ & 148 & [53] \\
\hline Graphene/cellulose nanofibers & 227.27 & [28] & $\begin{array}{l}\text { Polyacrylamide grafted } \\
\text { quaternized cellulose }\end{array}$ & 349.28 & [54] \\
\hline $\begin{array}{l}\mathrm{GO} / \text { calcium alginate } \\
\text { composites }\end{array}$ & 181.81 & [55] & $\mathrm{CaCO}_{3}$-cellulose aerogel & 75.81 & [56] \\
\hline
\end{tabular}




\subsection{Adsorption of Dyes in Binary Systems}

Regarding industrial wastewater, different types of dyes could be found and they compete for the adsorption sites on the surface of the adsorbent. To investigate the adsorption capacity of CNF-GnP in a more practical setting, an $\mathrm{MB}$ and $\mathrm{CR}$ binary system was prepared and investigated. The mass ratio of $\mathrm{MB}$ to $\mathrm{CR}$ in the solution was designed to be 3:1,1:1 and 1:3. The total initial dye concentration was set to be $200 \mathrm{mg} \mathrm{L}^{-1}$. The adsorption of dye in single and binary systems was compared (Figure 7). Shown in Figure 7a, when the mass ratio of $\mathrm{MB}$ to $\mathrm{CR}$ was 3:1 (i.e., $\mathrm{MB}=150 \mathrm{mg} \mathrm{L}^{-1}, \mathrm{CR}=50 \mathrm{mg} \mathrm{L}^{-1}$ ), the adsorption of MB onto pure CNF in the binary system was lower than that in the single system, indicating $\mathrm{MB}$ and $\mathrm{CR}$ competed for adsorption sites on the CNF surface. However, the adsorption of $\mathrm{MB}$ onto pure $\mathrm{GnP}$ and $\mathrm{CNF}-\mathrm{GnP}$ was similar in both the single and binary systems. The adsorption of $\mathrm{CR}$ onto all adsorbents increased in the binary system compared to that in the single system. This may be attributed to the Coulombic attraction between cationic MB adsorbed on the material surface and anionic CR in solution. Similarly, when the mass ratio of MB to CR was 1:1 (Figure 7b), the adsorption of MB was lower and the CR uptake for pure CNF and CNF-GnP was higher in the binary system than in the single system. However, the adsorption of $\mathrm{CR}$ onto pure $\mathrm{GnP}$ was strongly affected by the presence of $\mathrm{MB}$ when the $\mathrm{CR}$ concentration increased. Moreover, when $\mathrm{CR}$ became the dominant molecule in the binary system (i.e., $\mathrm{MB}$ to $\mathrm{CR}$ ratio was 1:3, Figure $7 \mathrm{c}$ ), the $\mathrm{CNF}-\mathrm{GnP}$ hybrid was able to adsorb even more $\mathrm{CR}$ than pure GnP. Regarding all binary systems, the adsorption capacity of CNF-GnP was the best among the different nano adsorbents, and the presence of one dye had no negative impact on the adsorption of the other dye. The hybrid CNF-GnP adsorbed the highest amount of $\mathrm{MB}$ and $\mathrm{CR}$ combined per unit mass of adsorbent. Perhaps the cationic MB and anionic $\mathrm{CR}$ adsorbed onto different types of adsorption sites on the CNF-GnP surface. The cationic MB mainly adsorbed onto the negatively charged CNF portion, while most of the CR adsorbed onto the GnP portion. $\mathrm{MB}$ adsorbed on the material surface also may attract anionic $C R$ in solution via Coulombic attraction.

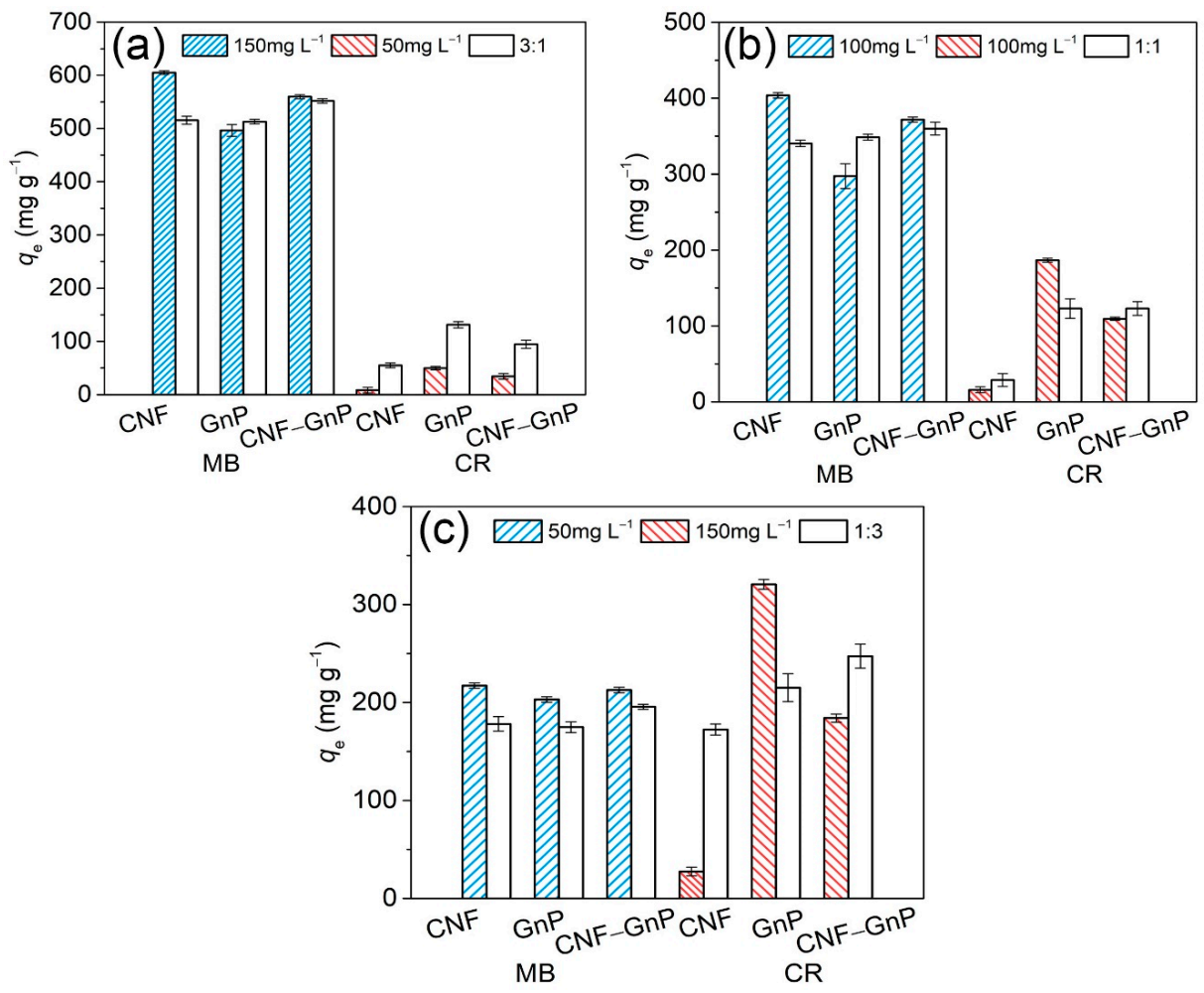

Figure 7. Adsorption of $\mathrm{MB}$ and $\mathrm{CR}$ in single and binary dye solution. (a) mass ratios of $\mathrm{MB}$ to $C R$ are $3: 1$; (b) mass ratio of $M B$ to $C R$ are 1:1; (c) mass ratio of $M B$ to $C R$ are 1:3. Colored bars represent adsorption in a single dye system. Colorless bars represent adsorption of one dye in a binary dye system. 


\subsection{Desorption}

The desorption of $\mathrm{MB}$ and $\mathrm{CR}$ from $\mathrm{CNF}, \mathrm{GnP}$ and $\mathrm{CNF}-\mathrm{GnP}$ by ethanol, acetonitrile, acetone and $400 \mathrm{mM} \mathrm{NaCl}$ was investigated. The desorption of dye adhered onto CNF, GnP and CNF-GnP was not effective using acetonitrile, acetone and $\mathrm{NaCl}$. Upon immersion in acetonitrile, acetone or $400 \mathrm{mM}$ $\mathrm{NaCl}$ for $1 \mathrm{~h}$, only $23.6 \%, 17.2 \%$ or $28.3 \%$ of pre-adsorbed MB in CNF-GnP hybrid (100 mg L $\mathrm{m}^{-1} \mathrm{MB}$, $20 \mathrm{~mL} \mathrm{MB}$ solution, $16 \mathrm{~h}$ ) was desorbed, respectively. Upon immersion in acetone or $400 \mathrm{mM} \mathrm{NaCl}$, only $6.0 \%$ or $20.1 \%$ of pre-adsorbed MB in GnP was desorbed. Concerning CNF, only $36.6 \% \mathrm{MB}$ was desorbed by acetone. Although $400 \mathrm{mM} \mathrm{NaCl}$ could desorb $88.6 \% \mathrm{MB}$ under the same conditions, the pure $\mathrm{CNF}$ aerogel could not remain intact after immersion for $1 \mathrm{~h}$. Strong ionic conditions destroyed the hydrogen bonding network in pure CNF. Dyes adhered to CNF, GnP and CNF-GnP were desorbed rapidly by ethanol (Figure 8). Desorption of $\mathrm{MB}$ and $\mathrm{CR}$ adhered to CNF-GnP by ethanol was relatively more effective. After $1 \mathrm{~h}$ of immersion, $42.4 \%$ of the $\mathrm{MB}$ and $51.0 \%$ of the $\mathrm{CR}$ were desorbed from CNF-GnP by ethanol. Finally, after four rounds of desorption, $79.2 \%$ of the MB and $78.3 \%$ of the CR were desorbed. Anhydrous ethanol is a protic solvent that contains polarized oxyhydrogen bonds which ionize to form alkoxyl negative ions and protons (hydrogen ions). It can provide lone pair electron interaction with MB (cationic dye) molecules. Concurrently, anhydrous ethanol also can provide protons with $\mathrm{CR}$ (anionic dye) molecules to form hydrogen bonds. The rapid desorption of both MB and CR demonstrate that the CNF-GnP hybrid aerogel could be easily regenerated for repeated dye removal applications.
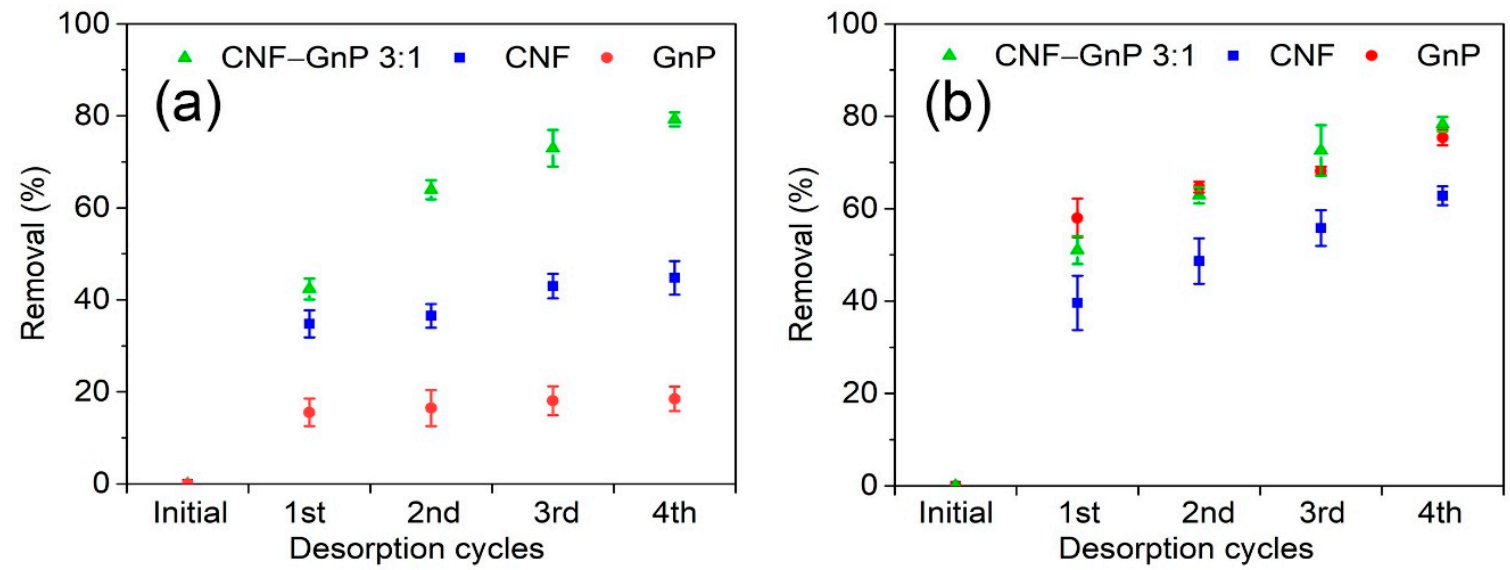

Figure 8. Cyclic desorption of MB (a) and CR (b) with CNF-GnP, CNF, GnP by ethanol.

\section{Conclusions}

Hybrid aerogels containing TEMPO oxidized cellulose nanofibrils (CNFs) and carbon nanomaterials (carbon nanotubes (CNTs) or graphene nanoplates $(\mathrm{GnPs})$ ), were designed and synthesized by freeze-drying to remove organic dyes from single and binary systems. When the CNF to GnP mass ratio was 3:1, the hybrid aerogel exhibited the most effective adsorption of both methylene blue $(\mathrm{MB})$ and Congo red $(\mathrm{CR})$ among all the hybrid systems tested. The final adsorption capacities of CNF-GnP 3:1 aerogels for MB and CR reached $1166.1 \mathrm{mg} \mathrm{g}^{-1}$ and $507.1 \mathrm{mg} \mathrm{g}^{-1}$ at initial dye concentrations of $500 \mathrm{mg} \mathrm{L}^{-1}$ and $2000 \mathrm{mg} \mathrm{L}^{-1}$, respectively. The CNFs enhanced the dispersion of carbon nanomaterials in an aqueous environment. The hybrid aerogels were mechanically strong and exhibited water-activated shape recovery. Seen in a single dye adsorption system, the adsorption ability measurements demonstrate that the CNF-GnP 3:1 aerogel possessed the adsorption capacity and adsorption rate close to $\mathrm{CNF}$ aerogels in cationic $\mathrm{MB}$ solutions. The adsorption capacity and adsorption rate of CNF-GnP aerogels was more efficient than the CNF aerogel in an anionic CR solution. Dye adsorptions to CNF-GnP followed a pseudo-second-order adsorption kinetic and the existence of $\mathrm{CNF}$ did not affect the adsorption kinetics of GnP. The adsorption followed a monolayer 
Langmuir isotherm. Concerning a binary system, the CNF-GnP aerogel removed cationic MB as well as anionic $\mathrm{CR}$ at a higher total dye adsorption capacity than pristine CNF or GnP. Moreover, 79.2\% and $78.3 \%$ of the $\mathrm{MB}$ and $\mathrm{CR}$ were desorbed from $\mathrm{CNF}-\mathrm{GnP}$ by using ethanol as the desorption agent, suggesting the reusability of this hybrid material. Results of this study indicate that CNF-GnP show promise as high-potential adsorbents for organic dye removal.

Supplementary Materials: The following are available online at http://www.mdpi.com/2079-4991/10/1/169/s1, Figure S1: Conductometric titration curves of CNF (a) with $\mathrm{HCl}$ added and (b) without $\mathrm{HCl}$ added., Figure S2: Optical micrographs of (a) CNF/CNT 3:1 after 5 min ultrasonic treatment; (b) CNF/CNT 3:1 after 30 min ultrasonic treatment; and (c) CNF/GnP 3:1 after 5 min of ultrasonic treatment; (d) CNF/GnP 3:1 after 30 min ultrasonic treatment, Table S1: Chemical structure, molecular weight, maximum absorption wavelength and electrical property of methylene blue and Congo red. Table S2: Group statistics of the final adsorption of MB. Table S3: Independent sample tests of the final adsorption of MB onto CNF-GnP 3:1 and CNF-CNT 3:1. Table S4: Group statistics of the final adsorption of CR. Table S5: Independent sample tests of the final adsorption of CR onto CNF-GnP 3:1 and CNF-CNT 3:1. Movie S1: Shape recovery of CNF aerogel in water after compression. Movie S2: Shape recovery of CNF-CNT aerogel in water after compression. Movie S3: Shape recovery of CNF-GnP aerogel in water after compression in water.

Author Contributions: Conceptualization, J.G.; methodology, A.B.D.; investigation, Z.Y. and W.J.; data curation, Z.Y.; writing — original draft preparation, Z.Y.; writing—review and editing, J.G. and A.B.D.; supervision, C.H.; funding acquisition, C.H. and J.G. All authors have read and agreed to the published version of the manuscript.

Funding: This research was funded by Guangzhou Science and Technology Bureau, grant number 201904010308, the Guangdong Government Science and Technology, grant number 2017 B020238003 and Bureau of Guangdong Forestry, grant number 2017-LYBZ-012.

Conflicts of Interest: The authors declare no conflict of interest.

\section{References}

1. Ahmed, M.J. Application of agricultural based activated carbons by microwave and conventional activations for basic dye adsorption: Review. J. Environ. Chem. Eng. 2016, 4, 89-99. [CrossRef]

2. Mohammed, N.; Grishkewich, N.; Berry, R.M.; Tam, K.C. Cellulose nanocrystal-alginate hydrogel beads as novel adsorbents for organic dyes in aqueous solutions. Cellulose 2015, 22, 3725-3738. [CrossRef]

3. Tan, I.A.W.; Ahmad, A.L.; Hameed, B.H. Adsorption of basic dye using activated carbon prepared from oil palm shell: Batch and fixed bed studies. Desalination 2008, 225, 13-28. [CrossRef]

4. Purkait, M.K.; Maiti, A.; DasGupta, S.; De, S. Removal of congo red using activated carbon and its regeneration. J. Hazard. Mater. 2007, 145, 287-295. [CrossRef] [PubMed]

5. Singh, N.B.; Nagpal, G.; Agrawal, S. Water purification by using Adsorbents: A Review. Environ. Technol. Innov. 2018, 11, 187-240. [CrossRef]

6. Gu, J.; Hu, C.; Zhang, W.; Dichiara, A. Reagentless preparation of shape memory cellulose nanofibril aerogels decorated with Pd nanoparticles and their application in dye discoloration. Appl. Catal. B Environ. 2018, 237, 482-490. [CrossRef]

7. Dante, R.C.; Martín-Ramos, P.; Chamorro-Posada, P.; Meejoo-Smith, S.; Vázquez-Cabo, J.; Rubiños-López, Ó.; Lartundo-Rojas, L.; Sánchez-Árevalo, F.M.; Trakulmututa, J.; Rutto, D.; et al. Comparison of the activities of C2N and BCNO towards Congo red degradation. Mater. Chem. Phys. 2019, 221, 397-408. [CrossRef]

8. Zhu, X.; Liu, Y.; Zhou, C.; Zhang, S.; Chen, J. Novel and High-Performance Magnetic Carbon Composite Prepared from Waste Hydrochar for Dye Removal. ACS Sustain. Chem. Eng. 2014, 2, 969-977. [CrossRef]

9. Ma, J.; Yu, F.; Zhou, L.; Jin, L.; Yang, M.; Luan, J.; Tang, Y.; Fan, H.; Yuan, Z.; Chen, J. Enhanced Adsorptive Removal of Methyl Orange and Methylene Blue from Aqueous Solution by Alkali-Activated Multiwalled Carbon Nanotubes. ACS Appl. Mat. Interfaces 2012, 4, 5749-5760. [CrossRef]

10. Moradi, O. Adsorption Behavior of Basic Red 46 by Single-Walled Carbon Nanotubes Surfaces. Fuller. Nanotub. Carbon Nanostruct. 2013, 21, 286-301. [CrossRef]

11. Zare, K.; Sadegh, H.; Shahryari-Ghoshekandi, R.; Maazinejad, B.; Ali, V.; Tyagi, I.; Agarwal, S.; Gupta, V.K. Enhanced removal of toxic Congo red dye using multi walled carbon nanotubes: Kinetic, equilibrium studies and its comparison with other adsorbents. J. Mol. Liq. 2015, 212, 266-271. [CrossRef] 
12. Yu, J.; Yu, L.; Yang, H.; Liu, Q.; Chen, X.; Jiang, X.; Chen, X.; Jiao, F. Graphene nanosheets as novel adsorbents in adsorption, preconcentration and removal of gases, organic compounds and metal ions. Sci. Total Environ. 2015, 502, 70-79. [CrossRef] [PubMed]

13. Bolotin, K.I.; Sikes, K.J.; Jiang, Z.; Klima, M.; Fudenberg, G.; Hone, J.; Kim, P.; Stormer, H.L. Ultrahigh electron mobility in suspended graphene. Solid State Commun. 2008, 146, 351-355. [CrossRef]

14. Yang, K.; Wang, J.; Chen, X.; Zhao, Q.; Ghaffar, A.; Chen, B. Application of graphene-based materials in water purification: From the nanoscale to specific devices. Environ. Sci. Nano 2018, 5, 1264-1297. [CrossRef]

15. Pan, X.; Du, Q.; Zhou, Y.; Liu, L.; Xu, G.; Yan, C. Ammonia Borane Promoted Synthesis of Graphene Aerogels as High Efficient Dye Adsorbent. J. Nanosci. Nanotechnol. 2018, 18, 7231-7240. [CrossRef]

16. Kim, H.; Kang, S.-O.; Park, S.; Park, H.S. Adsorption isotherms and kinetics of cationic and anionic dyes on three-dimensional reduced graphene oxide macrostructure. J. Ind. Eng. Chem. 2015, 21, 1191-1196. [CrossRef]

17. Dichiara, A.B.; Benton-Smith, J.; Rogers, R.E. Enhanced adsorption of carbon nanocomposites exhausted with 2, 4-dichlorophenoxyacetic acid after regeneration by thermal oxidation and microwave irradiation. Environ. Sci. Nano 2014, 1, 113-116. [CrossRef]

18. Li, D.; Mueller, M.B.; Gilje, S.; Kaner, R.B.; Wallace, G.G. Processable aqueous dispersions of graphene nanosheets. Nat. Nanotechnol. 2008, 3, 101-105. [CrossRef]

19. Mahfoudhi, N.; Boufi, S. Nanocellulose as a novel nanostructured adsorbent for environmental remediation: A review. Cellulose 2017, 24, 1171-1197. [CrossRef]

20. Gu, J.; Catchmark, J.M.; Kaiser, E.Q.; Archibald, D.D. Quantification of cellulose nanowhiskers sulfate esterification levels. Carbohydr. Polym. 2013, 92, 1809-1816. [CrossRef]

21. Gu, J.; Hsieh, Y.-L. Surface and Structure Characteristics, Self-Assembling, and Solvent Compatibility of Holocellulose Nanofibrils. ACS Appl. Mater. Interfaces 2015, 7, 4192-4201. [CrossRef] [PubMed]

22. Jiang, F.; Dinh, D.M.; Hsieh, Y.-L. Adsorption and desorption of cationic malachite green dye on cellulose nanofibril aerogels. Carbohydr. Polym. 2017, 173, 286-294. [CrossRef] [PubMed]

23. Jin, L.; Sun, Q.; Xu, Q.; Xu, Y. Adsorptive removal of anionic dyes from aqueous solutions using microgel based on nanocellulose and polyvinylamine. Bioresour. Technol. 2015, 197, 348-355. [CrossRef] [PubMed]

24. Hamedi, M.M.; Hajian, A.; Fall, A.B.; Håkansson, K.; Salajkova, M.; Lundell, F.; Wågberg, L.; Berglund, L.A. Highly Conducting, Strong Nanocomposites Based on Nanocellulose-Assisted Aqueous Dispersions of Single-Wall Carbon Nanotubes. ACS Nano 2014, 8, 2467-2476. [CrossRef] [PubMed]

25. Jing-Quan, H.; Kai-Yue, L.; Yi-Ying, Y.; Chang-Tong, M.; Hui-Xiang, W.; Peng-Bin, Y.; Xin-Wu, X. Synthesis and electrochemical performance of flexible cellulose nanofiber-carbon nanotube/natural rubber composite elastomers as supercapacitor electrodes. New Carbon Mater. 2018, 33, 341-350.

26. Hajian, A.; Lindström, S.B.; Pettersson, T.; Hamedi, M.M.; Wågberg, L. Understanding the Dispersive Action of Nanocellulose for Carbon Nanomaterials. Nano Lett. 2017, 17, 1439-1447. [CrossRef]

27. Wei, X.; Huang, T.; Yang, J.-H.; Zhang, N.; Wang, Y.; Zhou, Z.-W. Green synthesis of hybrid graphene oxide/microcrystalline cellulose aerogels and their use as superabsorbents. J. Hazard. Mater. 2017, 335, $28-38$. [CrossRef]

28. Hussain, A.; Li, J.; Wang, J.; Xue, F.; Chen, Y.; Bin Aftab, T.; Li, D. Hybrid Monolith of Graphene/TEMPO-Oxidized Cellulose Nanofiber as Mechanically Robust, Highly Functional, and Recyclable Adsorbent of Methylene Blue Dye. J. Nanomater. 2018, 2018, 1-12. [CrossRef]

29. Wu, H.; Wang, Z.-M.; Kumagai, A.; Endo, T. Amphiphilic cellulose nanofiber-interwoven graphene aerogel monolith for dyes and silicon oil removal. Compos. Sci. Technol. 2019, 171, 190-198. [CrossRef]

30. Goodman, S.M.; Ferguson, N.; Dichiara, A.B. Lignin-assisted double acoustic irradiation for concentrated aqueous dispersions of carbon nanotubes. RSC Adv. 2017, 7, 5488-5496. [CrossRef]

31. Lu, P.; Hsieh, Y.L. Preparation and characterization of cellulose nanocrystals from rice straw. Carbohydr. Polym. 2012, 87, 564-573. [CrossRef]

32. Gu, J.; Hsieh, Y.-L. Alkaline cellulose nanofibrils from streamlined alkali treated rice straw. ACS Sustain. Chem. Eng. 2017, 5, 1730-1737. [CrossRef]

33. Isogai, A.; Saito, T.; Fukuzumi, H. TEMPO-oxidized cellulose nanofibers. Nanoscale 2011, 3, 71-85. [CrossRef] [PubMed] 
34. Wan, W.; Zhang, R.; Li, W.; Liu, H.; Lin, Y.; Li, L.; Zhou, Y. Graphene-Carbon nanotube aerogel as an ultra-light, compressible and recyclable highly efficient absorbent for oil and dyes. Environ. Sci. Nano 2016, 3, 107-113. [CrossRef]

35. Mahmoodi, N.M.; Hayati, B.; Arami, M.; Mazaheri, F. Single and Binary System Dye Removal from Colored Textile Wastewater by a Dendrimer as a Polymeric Nanoarchitecture: Equilibrium and Kinetics. J. Chem. Eng. Data 2010, 55, 4660-4668. [CrossRef]

36. Mahmoodi, N.M.; Hayati, B.; Arami, M. Textile Dye Removal from Single and Ternary Systems Using Date Stones: Kinetic, Isotherm, and Thermodynamic Studies. J. Chem. Eng. Data 2010, 55, 4638-4649. [CrossRef]

37. Chen, L.; Han, Q.; Li, W.; Zhou, Z.; Fang, Z.; Xu, Z.; Wang, Z.; Qian, X. Three-Dimensional graphene-Based adsorbents in sewage disposal: A review. Environ. Sci. Pollut. Res. 2018, 25, 25840-25861. [CrossRef]

38. Zhang, X.; Liu, D.; Sui, G. Superamphiphilic Polyurethane Foams Synergized from Cellulose Nanowhiskers and Graphene Nanoplatelets. Adv. Mater. Interfaces 2018, 5, 1701094. [CrossRef]

39. Dai, J.; Huang, T.; Tian, S.-Q.; Xiao, Y.-J.; Yang, J.-H.; Zhang, N.; Wang, Y.; Zhou, Z.-W. High structure stability and outstanding adsorption performance of graphene oxide aerogel supported by polyvinyl alcohol for waste water treatment. Mater. Des. 2016, 107, 187-197. [CrossRef]

40. Dichiara, A.B.; Song, A.; Goodman, S.M.; He, D.; Bai, J. Smart papers comprising carbon nanotubes and cellulose microfibers for multifunctional sensing applications. J. Mater. Chem. A 2017, 5, 20161-20169. [CrossRef]

41. Lagergren, S. Zur theorie der sogenannten adsorption gelosterstoffeKungliga Svenska Vetenskapsakademiens. Handlingar 1898, 24, 1-39.

42. Ho, Y.S.; McKay, G. Pseudo-second order model for sorption processes. Process. Biochem. 1999, 5, 451-465. [CrossRef]

43. Liu, T.; Li, Y.; Du, Q.; Sun, J.; Jiao, Y.; Yang, G.; Wang, Z.; Xia, Y.; Zhang, W.; Wang, K.; et al. Adsorption of methylene blue from aqueous solution by graphene. Colloids Surf. B 2012, 90, 197-203. [CrossRef] [PubMed]

44. Ansari, M.O.; Kumar, R.; Ansari, S.A.; Ansari, S.P.; Barakat, M.A.; Alshahrie, A.; Cho, M.H. Anion selective pTSA doped polyaniline@graphene oxide-multiwalled carbon nanotube composite for $\mathrm{Cr}(\mathrm{VI})$ and Congo red adsorption. J. Colloid Interface Sci. 2017, 496, 407-415. [CrossRef] [PubMed]

45. Dichiara, A.B.; Sherwood, T.J.; Rogers, R.E. Binder free graphene-single-wall carbon nanotube hybrid papers for the removal of polyaromatic compounds from aqueous systems. J. Mater. Chem. A 2013, 1, 14480-14483. [CrossRef]

46. Langmuir, I. The adsorption of gases on plane surfaces of glass, mica andplatinum. J. Am. Chem. Soc. 1918, 40, 42. [CrossRef]

47. Freundlich, H. Veber die adsorption in loesungen (Adsorption in solution). Z. Phys. Chem. 1907, 57, 385-470.

48. Foo, K.Y.; Hameed, B.H. Insights into the modeling of adsorption isotherm systems. Chem. Eng. J. 2010, 156, 2-10. [CrossRef]

49. Khanday, W.A.; Marrakchi, F.; Asif, M.; Hameed, B.H. Mesoporous zeolite-Activated carbon composite from oil palm ash as an effective adsorbent for methylene blue. J. Taiwan Inst. Chem. Eng. 2017, 70, 32-41. [CrossRef]

50. Jin, L.; Zhao, X.; Qian, X.; Dong, M. Nickel nanoparticles encapsulated in porous carbon and carbon nanotube hybrids from bimetallic metal-organic-frameworks for highly efficient adsorption of dyes. J. Colloid Interface Sci. 2017, 509, S0021979717310226. [CrossRef] [PubMed]

51. Chatterjee, S.; Lee, M.W.; Woo, S.H. Adsorption of congo red by chitosan hydrogel beads impregnated with carbon nanotubes. Bioresour. Technol. 2010, 101, 1800-1806. [CrossRef] [PubMed]

52. Zhang, X.; Liu, D.; Yang, L.; Zhou, L.; You, T. Self-assembled three-dimensional graphene-based materials for dye adsorption and catalysis. J. Mater. Chem. A 2015, 3, 10031-10037. [CrossRef]

53. Gupta, V.K.; Kumar, R.; Nayak, A.; Saleh, T.A.; Barakat, M.A. Adsorptive removal of dyes from aqueous solution onto carbon nanotubes: A review. Adv. Colloid Interface Sci. 2013, 193-194, 24-34. [CrossRef] [PubMed]

54. Wang, Y.; Zhao, L.; Peng, H.; Wu, J.; Liu, Z.; Guo, X. Removal of Anionic Dyes from Aqueous Solutions by Cellulose-Based Adsorbents: Equilibrium, Kinetics, and Thermodynamics. J. Chem. Eng. Data 2016, 61, 3266-3276. [CrossRef] 
55. Li, Y.; Du, Q.; Liu, T.; Sun, J.; Wang, Y.; Wu, S.; Wang, Z.; Xia, Y.; Xia, L. Methylene blue adsorption on graphene oxide/calcium alginate composites. Carbohydr. Polym. 2013, 95, 501-507. [CrossRef] [PubMed]

56. Chong, K.Y.; Chia, C.H.; Zakaria, S.; Sajab, M.S.; Chook, S.W.; Khiew, P.S. CaCO3-decorated cellulose aerogel for removal of Congo Red from aqueous solution. Cellulose 2015, 22, 2683-2691. [CrossRef]

(C) 2020 by the authors. Licensee MDPI, Basel, Switzerland. This article is an open access article distributed under the terms and conditions of the Creative Commons Attribution (CC BY) license (http://creativecommons.org/licenses/by/4.0/). 